\title{
Genetic Suppression of Transgenic APP Rescues Hypersynchronous Network Activity in a Mouse Model of Alzeimer's Disease
}

\author{
Heather A. Born, ${ }^{1}$ Ji-Yoen Kim, ${ }^{1}$ Ricky R. Savjani, ${ }^{1,8}$ Pritam Das, ${ }^{9}$ Yuri A. Dabaghian, ${ }^{6,10}$ Qinxi Guo, ${ }^{7}$ Jong W. Yoo, ${ }^{2}$ \\ Dorothy R. Schuler, ${ }^{11}$ John R. Cirrito, ${ }^{11}$ Hui Zheng, ${ }^{1,3,4,7}$ Todd E. Golde, ${ }^{12}$ Jeffrey L. Noebels, ${ }^{1,2,4}$ \\ and Joanna L. Jankowsky ${ }^{1,2,5,7}$ \\ ${ }^{1}$ Department of Neuroscience, ${ }^{2}$ Department of Neurology, ${ }^{3}$ Department of Molecular and Cellular Biology, ${ }^{4}$ Department of Human and Molecular Genetics, \\ ${ }^{5}$ Department of Neurosurgery, ${ }^{6}$ the Jan and Dan Duncan Neurological Research Institute, and ${ }^{7}$ the Huffington Center on Aging, Baylor College of Medicine, \\ Houston, Texas 77030, ${ }^{8}$ Texas A\&M Health Science Center, College Station, Texas 77843, ${ }^{9}$ Department of Neuroscience, Mayo Clinic, Jacksonville, Florida \\ 32224, ${ }^{10}$ Department of Computational and Applied Mathematics, Rice University, Houston, Texas 77251, ${ }^{11}$ Department of Neurology, Washington \\ University School of Medicine, St. Louis, Missouri 63110, and ${ }^{12}$ Department of Neuroscience, University of Florida, Gainesville, Florida 32610
}

\begin{abstract}
Alzheimer's disease $(\mathrm{AD})$ is associated with an elevated risk for seizures that may be fundamentally connected to cognitive dysfunction. Supporting this link, many mouse models for AD exhibit abnormal electroencephalogram (EEG) activity in addition to the expected neuropathology and cognitive deficits. Here, we used a controllable transgenic system to investigate how network changes develop and are maintained in a model characterized by amyloid $\beta(\mathrm{A} \beta)$ overproduction and progressive amyloid pathology. EEG recordings in tet-off mice overexpressing amyloid precursor protein (APP) from birth display frequent sharp wave discharges (SWDs). Unexpectedly, we found that withholding APP overexpression until adulthood substantially delayed the appearance of epileptiform activity. Together, these findings suggest that juvenile APP overexpression altered cortical development to favor synchronized firing. Regardless of the age at which EEG abnormalities appeared, the phenotype was dependent on continued APP overexpression and abated over several weeks once transgene expression was suppressed. Abnormal EEG discharges were independent of plaque load and could be extinguished without altering deposited amyloid. Selective reduction of A $\beta$ with a $\gamma$-secretase inhibitor has no effect on the frequency of SWDs, indicating that another APP fragment or the full-length protein was likely responsible for maintaining EEG abnormalities. Moreover, transgene suppression normalized the ratio of excitatory to inhibitory innervation in the cortex, whereas secretase inhibition did not. Our results suggest that $\mathrm{APP}$ overexpression, and not $\mathrm{A} \beta$ overproduction, is responsible for EEG abnormalities in our transgenic mice and can be rescued independently of pathology.
\end{abstract}

Key words: amyloid precursor protein; EEG; epilepsy; seizure; sharp wave discharge; transgene suppression

\section{Introduction}

A growing body of evidence suggests that Alzheimer's disease (AD) increases the risk for seizures above the rise connected with aging. Late-onset sporadic AD is associated with a threefold in-

\footnotetext{
Received Dec. 10, 2013; revised Jan. 10, 2014; accepted Jan. 30, 2014.

Author contributions: H.A.B., J.-Y.K., and J.L.J. designed research; H.A.B., J.-Y.K., P.D., J.W.Y., D.R.S., and J.R.C. performed research; Q.G., H.Z., and T.E.G. contributed unpublished reagents/analytic tools; H.A.B., J.-Y.K., R.R.S., P.D., Y.A.D., J.R.C., and J.L.N. analyzed data; H.A.B. and J.L.J. wrote the paper.

This work was funded by the National Institutes of Health (Office of the Director New Innovator Award DP2 OD001734 to J.L.J.). H.A.B. was supported by the National Institute of Aging Biology of Aging (Training Grant T32 AG000183) and by a gift from the family of Mr. RobertL. Cook. We thank Rich Paylor for sharing telemetry equipment used in this study; Cynthia Evans for creative support of our vivarium needs; Corey Reynolds and the BCM Mouse Phenotyping Core for help with initial telemetry recordings; Philip Jones for chemical analysis of inhibitor syntheses; and Anna Gumpel, Carolyn Allen, Yuanyuan Zhang, Bryan Song, and Anna Kuperman for careful oversight of the mouse colony.

The authors declare no competing financial interests.

Correspondence should be addressed to Joanna L. Jankowsky, Baylor College of Medicine, BCM295, One Baylor Plaza, Houston, TX77030. E-mail: jankowsk@bcm.edu.

DOI:10.1523/JNEUROSCI.5171-13.2014

Copyright $\odot 2014$ the authors $\quad 0270-6474 / 14 / 343826-15 \$ 15.00 / 0$
}

crease in seizure incidence compared with the general population, whereas early-onset familial AD is linked to an astonishing 87-fold rise (Amatniek et al., 2006). Seizure disorders and epilepsy are especially pronounced in families with presenilin mutations, in which nearly $30 \%$ of patients display this comorbidity, rising to nearly $75 \%$ in cases of particularly aggressive variants with onset before age 40 (Snider et al., 2005; Larner and Doran, 2006; Jayadev et al., 2010). Recent studies suggest that electrical imbalance may contribute to cognitive deficits in $\mathrm{AD}$ and serve as a target for clinical intervention (Palop and Mucke, 2009). Consistent with this idea, mouse models for AD show improved spatial navigation and diminished anxiety after treatment with the antiepileptic drug levetiracetam (Sanchez et al., 2012). Similar benefit from levetiracetam was observed in a small pilot study of patients with mild cognitive impairment (Bakker et al., 2012).

The mechanism by which $\mathrm{AD}$ increases seizure risk has only recently been explored using mouse models for the disease. Spontaneous seizures and sharp wave discharges (SWDs) have been observed in several transgenic models expressing mutations in 
amyloid precursor protein (APP). The seizure phenotype is most often noted in models carrying the Swedish mutation, including Tg2576 (Westmark et al., 2008), APP23 (Lalonde et al., 2005), hAPPJ20 (Palop et al., 2007; Sanchez et al., 2012; Verret et al., 2012; Corbett et al., 2013), and APP/PS1dE9 (Minkeviciene et al., 2009; Ziyatdinova et al., 2011). The prominent amyloid phenotype of these models has pointed to amyloid $\beta(\mathrm{A} \beta)$ as the mechanistic link connecting AD with seizures (Palop and Mucke, 2010). Although bath application of exogenous $A \beta$ generally diminishes synaptic plasticity, it conversely increases electrical activity of excitatory neurons (Minkeviciene et al., 2009). Hippocampal neurons in transgenic APP mice display abnormal spontaneous activity well before plaque formation (Busche et al., 2012), with hyperactive foci persisting at the periphery of amyloid deposits in later stages of disease (Busche et al., 2008). In turn, this hyperactivity may increase synaptic exocytosis of $\mathrm{A} \beta$ (Kamenetz et al., 2003; Cirrito et al., 2005; Bero et al., 2011), placing $\mathrm{A} \beta$ at the center of a pathological feedback loop (Noebels, 2011).

$\mathrm{A} \beta$ may not be the only contributor to epileptogenesis in $\mathrm{AD}$ and its mouse models. Patients with APP duplication are at greater risk for seizure (Cabrejo et al., 2006), as are Down syndrome patients with dementia (Menéndez, 2005). Many AD mouse models also produce high levels of APP, making it difficult to distinguish whether $A \beta$ is solely responsible for seizure activity or if other APP fragments may also contribute. Moreover, unlike most AD patients, transgenic mice overexpress APP during cortical development, when the protein's synaptogenic properties may have unanticipated effects on circuit connectivity (YoungPearse et al., 2008; Wang et al., 2009; Zheng and Koo, 2011). Because of their intrinsic relationship, separating the impact of APP from that of $A \beta$ and amyloid has been experimentally challenging. Here, we used a controllable APP-transgenic model to separate these factors and evaluate how APP overexpression, A $\beta$ overproduction, and plaque formation each contribute to network hyperactivity.

\section{Materials and Methods}

\section{Mice}

We studied tetracycline-responsive APP-transgenic mice (APP/TTA) expressing a chimeric mouse APP with a humanized $\mathrm{A} \beta$ domain encoding the Swedish and Indiana mutations (MMRRC \#34845; Jankowsky et al., 2005 ) that had been mated to CaMKII $\alpha$-tTA line B mice expressing the tetracycline transactivator under control of the CaMKII $\alpha$ promoter (\#3010; Jackson Laboratories; Mayford et al., 1996). Single-transgenic (TTA only) and nontransgenic (NTG) cagemates were used as controls. Each line had been independently backcrossed to C57BL/6J for $>20$ generations before being intercrossed to generate stud males that were bred with C57BL/6J females to generate animals for study (Rodgers et al., 2012). Animals were housed on a $12 \mathrm{~h} / 12 \mathrm{~h}$ or $13 \mathrm{~h} / 11 \mathrm{~h}$ day/night cycle and were used for study between 3 and 12 months of age.

APP/PS1 double knock-in mice were created by crossing APP knock-in mice encoding a humanized $\mathrm{A} \beta$ domain flanked by the Swedish and London mutations with PS1 knock-in mice encoding the M146V mutation (Guo et al., 1999; Köhler et al., 2005). Both lines were maintained on a C57BL/6 J background and were 23-24 months of age at the time of study. All studies were gender balanced. All animal experiments were performed using protocols that were reviewed and approved by the Institutional Care and Use Committee at Baylor College of Medicine.

\section{Chronic EEG recording and analysis}

Direct EEG recording. One cohort of APP/TTA, TTA, and NTG mice were implanted for baseline EEG recordings using wired, two-lead subdural EEG. After anesthesia with Avertin, subdural recording electrodes were implanted bilaterally over the parietal cortices. Mice were allowed to recover for at least $24 \mathrm{~h}$ before recording. EEG signal was recorded over 3 $3 \mathrm{~h}$ sessions using the Stellate Harmonie system (Natus Medical). Data were sampled at $200 \mathrm{~Hz}$ over a frequency range of $0.3-70 \mathrm{~Hz}$. Recordings were analyzed manually for SWDs and seizures by a blinded observer.

Estimating the specificity and sensitivity of single-lead EEG recordings. For the semiquantitative experiments we had in mind, we needed an EEG system that would deliver high-throughput, chronic recording capability. Telemetric recording systems provided these advantages, but at the cost of spatial resolution: mouse-sized radiofrequency transmitters carried only one recording lead rather than the two or more used by traditional EEG equipment. To validate the accuracy of EEG data obtained from a single lead, we reanalyzed the recordings made with our dual-lead wired setup to count the number of SWDs detected by one lead against the number detected by both. This provided a rough estimate of the percentage of bilateral events that would be accurately detected by a single recording electrode, along with a measure of the number of false positives that would be detected in a single lead but not present bilaterally. We found that, as the number of SWDs increased, so also did the percentage of SWDs recorded bilaterally, such that for data beyond $\sim 30$ spikes $/ \mathrm{h},>90 \%$ of all spikes identified by one electrode were seen in both (Fig. 1). Because most of our APP/TTA recordings fell at or above this SWD frequency, we transitioned to telemetry for all subsequent EEG recordings.

Telemetric EEG and locomotor recording. All subsequent EEG experiments used wireless ETA-F10 transmitters (Data Sciences International) for chronic EEG recording and locomotor monitoring. After anesthesia with isoflurane, a $1 \mathrm{~cm}$ midline sagittal incision was made starting above the interaural line and extending along the neck to create a pocket for subcutaneous placement of the transmitter along the dorsal flank of the animal. The recording electrode (stereotaxic coordinates relative to bregma: $+2.5 \mathrm{~mm},-2.5 \mathrm{~mm})$ and ground electrode $(-1.0 \mathrm{~mm},+1.0 \mathrm{~mm})$ were implanted subdurally through small holes drilled in the skull and held in place with dental cement. Mice were provided with ketoprofen analgesic for $3 \mathrm{~d}$ after surgery and allowed to recover for $10 \mathrm{~d}$ before recording.

Mice remained in their home cage during overnight recording sessions. EEG signal was collected through radiofrequency receivers placed under each cage. Locomotor activity was also interpolated from this signal by monitoring changes in signal strength between the transmitter and receiver as the animal moved about the cage. Using this system, a movement count was triggered whenever the signal change exceeded a prespecified threshold. Locomotor data are therefore reported as arbitrary activity counts per hour. Locomotor data were acquired at a sampling rate of $16 \mathrm{~Hz}$; EEG data between 1 and $200 \mathrm{~Hz}$ were acquired at a sampling rate of $1 \mathrm{kHz}$ using the Dataquest A.R.T. system, versions 2.1 and 4.0 (Data Sciences International).

Automated EEG analysis. Three overnight recordings made over the course of a week were averaged to determine the baseline frequency of SWDs per hour for each mouse. EEG recordings were analyzed to include a balanced number of daylight and nighttime hours for a total of $12 \mathrm{~h}$ per session (from 3:00 to 9:00 A.M. and from 4:00 to 10:00 P.M.). EEG signal was filtered using a band pass of $0.3-70 \mathrm{~Hz}$. Automated analysis of SWDs was done using Neuroscore software version 2.1 (Data Science International). The baseline threshold for each recording was manually determined as the best fit line that includes the majority of the EEG trace using the period between 12:00 and 1:00 A.M. when a low frequency of SWDs was observed. To be counted as a SWD, an electrical event must be brief in duration (5-15 ms) and have a peak amplitude $2.5 \times$ greater than the average baseline range. The ETA-F10 transmitters also acquired data on animal movement during recording, which was analyzed using Neuroscore to report activity counts per hour.

\section{Power, entropy, and autocorrelation analyses}

Two time points were analyzed for each animal, once before (baseline) and once after 4 weeks of transgene suppression. Analysis of each condition was limited to data collected during a single $6 \mathrm{~h}$ session spanning 1 dark-light transition (3:00-9:00 A.M.). Data were not filtered before analysis. One animal was excluded from each genotype due to noise in 
A TTA

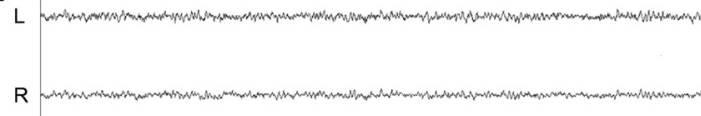

APP/TTA

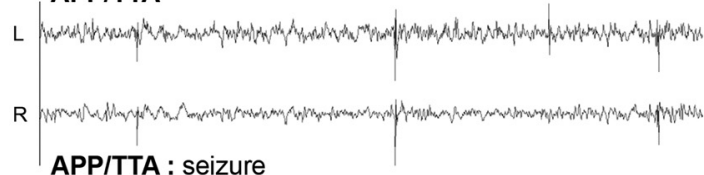

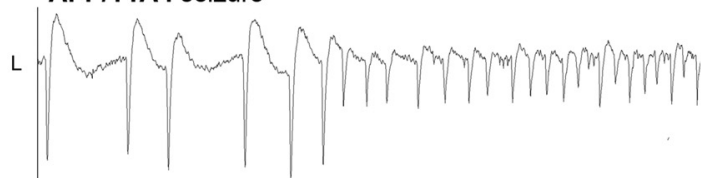

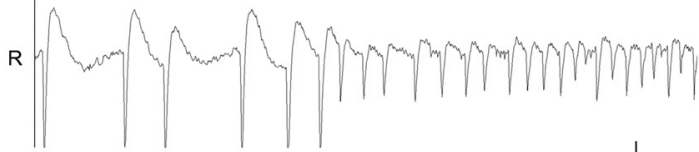

B NTG

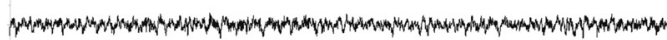

TTA

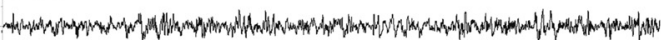

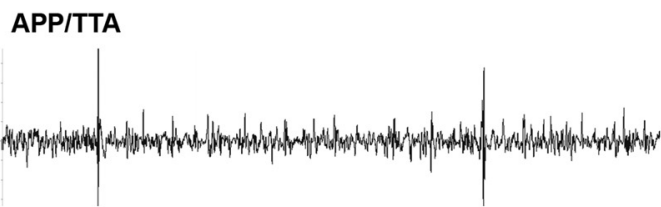

APP/TTA: seizure

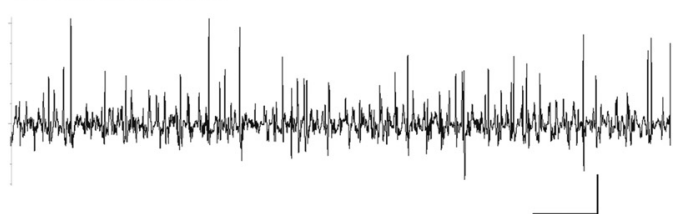

C

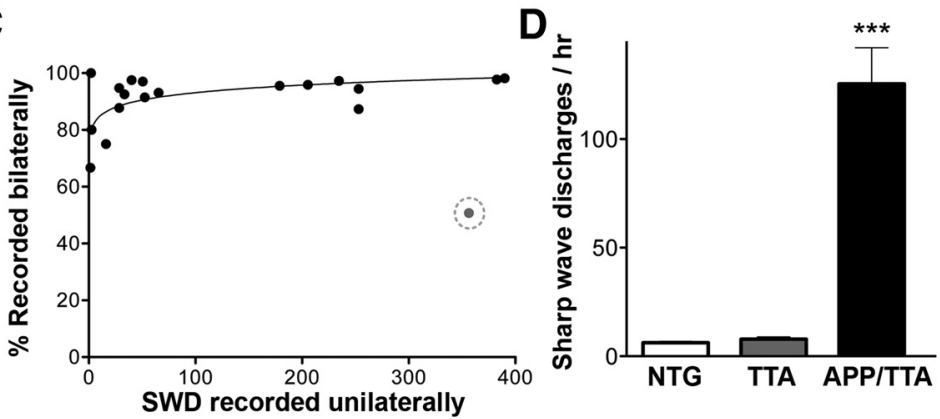

E

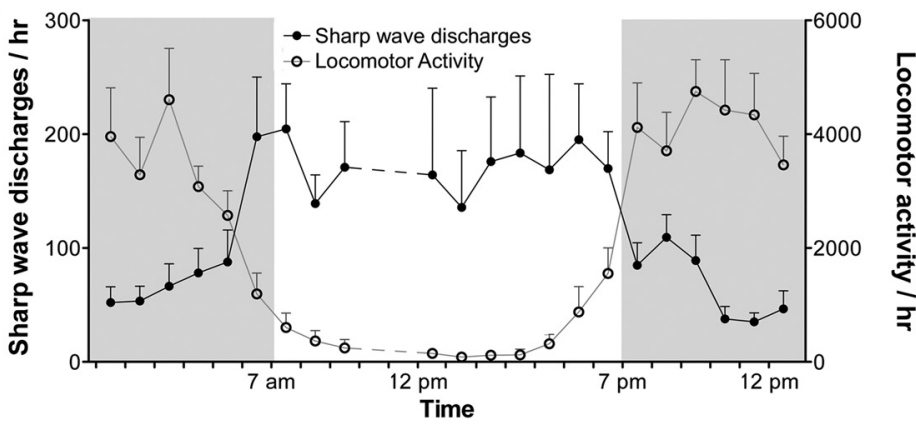

Figure 1. EEG recording reveals abnormal SWDs in tet-off APP-transgenic mice. $\boldsymbol{A}, \boldsymbol{B}$, EEG recordings made via wired dual-lead electrodes $(\boldsymbol{A})$ or by wireless radiofrequency transmitters ( $\boldsymbol{B}$ ) uncovered frequent SWDs and irregular seizure episodes in APP/TTA mice. Scale bars: $\boldsymbol{A}, 0.5 \mathrm{mV}$ and $2 \mathrm{~s} ; \boldsymbol{B}, 0.4 \mathrm{mV}$ and $2 \mathrm{~s}$. $\boldsymbol{C}$, Recordings made with dual-lead electrodes were used to assess the percentage of spikes that would be counted in error by moving to a single-lead setup. The graph illustrates the percentage of SWDs recorded bilaterally as a function of SWDs recorded unilaterally. As the number of spikes increased, $s 0$ also did the percentage of spikes recorded bilaterally. One data point (circled) was identified as an outlier and excluded from analysis. D, APP/TTA mice display a significantly higher number of SWDs/h than age-matched NTG and TTA controls. ${ }^{* *} p<0.001$. E, SWD frequency was inversely related to locomotor activity in APP/TTA mice. Black circles, SWDs; open circles, locomotor activity.

the signal that invalidated full-spectrum analyses, but this did not affect measurement of large-amplitude SWDs.

To characterize the spectral properties of the EEG signal in the WT and $\mathrm{AD}$ mice, we first normalized each signal by its $\mathrm{SD}$ and then computed the Fourier transform for each recording with an $8 \mathrm{~s}$ (8000 points) time window using the standard MATLAB Signal Processing toolbox (MathWorks). We calculated the normalized signal amplitude as a function of frequency between 0 and $300 \mathrm{~Hz}$ across the entire $6 \mathrm{~h}$ window. The results were then averaged for control and APP/TTA groups with no additional smoothing. Because the data were normalized before transformation, values are expressed as arbitrary units rather than $\mathrm{mV}^{2}$.

To characterize the entropy of peak timing in the EEG signal, we first isolated peak values $>3 \mathrm{SD}$ of the mean signal amplitude. These points were characterized by the time at which they occurred in the recording and used to calculate nearest-neighbor interpeak intervals. We next performed a sliding analysis of the data using a $17 \mathrm{~s}$ (17,000 points) window at a time. For each window, we plotted the distribution of interpeak intervals and from this calculated the entropy of the distribution according to the following equation:

$$
H=-\sum_{x} P(x) \log _{2} P(x)
$$

The window was then shifted by $0.1 \mathrm{~s}$ (100 points) and the entropies recomputed. By scanning the entire time axis in this way, we obtained entropy as a function of time. The results were averaged for each genotype and used to compute the entropy distributions shown in Figure 3. Both the amplitude threshold for defining signal peaks and the time 
window used for scanning the data were tested at multiple values and yielded similar results to the $3 \mathrm{SD} / 17 \mathrm{~s}$ analysis shown here.

Autocorrelation within the signal was tested for time lags ranging from 0 to $10 \mathrm{~s}$ (10,000 points) using MATLAB Signal Processing and Econometrics toolboxes. Group averages at each time lag were calculated and graphed as mean and SE.

\section{Doxycycline treatment}

To measure the effect of transgenic APP suppression on SWD frequency, one cohort of mice was treated with doxycycline (DOX) for 4-5 weeks after completion of baseline EEG recordings (F5903 $50 \mathrm{mg} / \mathrm{kg}$ DOX in TestDiet 5001 rodent chow; Purina).

A separate cohort of animals was used to measure the effect of delaying transgenic APP expression until adulthood on EEG activity. Mice used for adult onset studies were reared on DOX chow to suppress APP overexpression for the first 6 weeks of life, as described previously (Rodgers et al., 2012). At 6 weeks of age, mice were returned to unmedicated chow to initiate expression of transgenic APP. Thereafter, the transgene was continuously expressed until EEG testing.

\section{In vivo microdialysis}

The effect of DOX treatment on soluble $A \beta$ levels was determined using a separate cohort of mice implanted for microdialysis of interstitial fluid (ISF). Mice were unilaterally implanted with a $38 \mathrm{kDa}$ MW cutoff microdialysis probe ( $2 \mathrm{~mm}$ BR-style; Bioanalytical Systems) placing the probe tip into the hippocampus at a 12 degree angle $-3.1 \mathrm{~mm}$ from bregma, $-2.5 \mathrm{~mm}$ from midline, and $3.2 \mathrm{~mm}$ below the dura (Cirrito et al., 2003; Cirrito et al., 2011). Microdialysis perfusion buffer consisted of $4 \%$ albu$\mathrm{min}$ in artificial CSF at a flow rate of $1.0 \mu \mathrm{l} / \mathrm{min}$. Animals were allowed to recover for $6-8 \mathrm{~h}$ after probe insertion, and then 6 ISF A $\beta$ measurements were taken over a $6 \mathrm{~h}$ period. The mean concentration of exchangeable $\mathrm{A} \beta$ during this $6 \mathrm{~h}$ period was defined as the baseline ISF A $\beta$ concentration for each mouse. After basal $A \beta$ levels were determined, mice were administered DOX through their chow as above and microdialysis samples were taken into a refrigerated fraction collector every $1-3 \mathrm{~h}$ for the following $4 \mathrm{~d}$. After the final collection, samples were assayed for $\mathrm{A} \beta_{\mathrm{x}-40}$ and $\mathrm{A} \beta_{\mathrm{x}-42}$ by sandwich ELISA using an $\mathrm{A} \beta_{40}$ (mHF2)- or $\mathrm{A} \beta_{42}$-specific antibody (mHJ7.4) to capture the peptide, followed by a biotinylated central domain anti-A $\beta$ antibody (mHJ5.1) for detection (Cirrito et al., 2011). The concentration of ISF $A \beta$ in each sample was normalized to the baseline $\mathrm{A} \beta$ concentration for each mouse. At the end of the experiment, the brains were harvested and processed for histological verification of probe placement.

\section{$\gamma$-Secretase inhibition}

To test the efficacy of $\gamma$-secretase inhibition on steady-state levels of A $\beta$ in our mice, we administered young, predeposit APP/TTA mice (5-6 weeks of age) either a single intraperitoneal dose of LY411575 or 1 week of medicated chow. For acute treatment, the drug was dissolved in DMSO at $100 \mathrm{mg} / \mathrm{ml}$, diluted in corn oil to the appropriate concentration, and injected intraperitoneally to deliver $0,2.5,5,10$, or $20 \mathrm{mg} / \mathrm{kg}$. Mice were harvested 3-4 h after injection. Dosing for subchronic treatment was assessed by feeding mice chow compounded with LY411575 at $50 \mathrm{mg} / \mathrm{kg}$ to deliver 5 or $10 \mathrm{mg} / \mathrm{kg} / \mathrm{d}$. Mice were harvested after 1 week of treatment. From these dose-response studies, we decided to use a stepdown regimen in the aged cohort to test the effect of $\gamma$-secretase inhibition on EEG activity. After baseline recordings, aged APP/TTA and control mice were treated for 2 weeks with LY411575 compounded at a concentration of $50 \mathrm{mg} / \mathrm{kg}$ into Purina TestDiet 5001 chow to deliver 10 $\mathrm{mg} / \mathrm{kg} / \mathrm{d}$. After 2 weeks of treatment at $10 \mathrm{mg} / \mathrm{kg} / \mathrm{d}$, dosing was decreased to $5 \mathrm{mg} / \mathrm{kg} / \mathrm{d}$ for the remainder of the experiment.

\section{$A \beta$ ELISA}

To measure the dose response of LY411575 on soluble A $\beta$ levels, tissue was harvested from mice treated acutely or subchronically with LY411575 as described in $\gamma$-Secretase inhibition, above. Frozen hemiforebrain samples were homogenized by sonication in 7.5 volumes of TBS containing $1 \%$ Triton X-100 and $1 \times$ protease inhibitor mixture as described previously (Jankowsky et al., 2007). A $\beta$ levels were determined by end-specific sandwich ELISAs using monoclonal antibody 2.1.3 for capture (human $\mathrm{A} \beta \mathrm{x}-42$ specific) and HRP-conjugated monoclonal antibody Ab9 (human A $\beta 1-16$ specific) for detection or monoclonal antibody Ab9 for capture and HRP-conjugated monoclonal antibody 13.1.1 (human A $\beta \mathrm{x}-40$ specific) for detection (Levites et al., 2006a; Levites et al., $2006 \mathrm{~b}$ ). All values were calculated as picomoles per gram based on the initial weight of brain tissue.

\section{Seizure induction}

To determine whether APP overexpression altered the threshold for chemical seizure induction, mice were implanted with ETA-F10 transponders as described in Telemetric EEG and locomotor recording, above and recorded for pretreatment values before convulsant exposure. Picrotoxin (P1675; Sigma) was dissolved in sterile saline and injected subcutaneously at $1.75 \mathrm{mg} / \mathrm{kg}$. Mice were videotaped during EEG recording for $1 \mathrm{~h}$ after injection. A separate cohort of mice was treated with kainic acid (BML-EA123; VWR) injected subcutaneously at $35 \mathrm{mg} / \mathrm{kg}$ and recorded for $1 \mathrm{~h}$ after injection. Video recordings were reviewed to determine: (1) the latency to seizure onset, (2) the total number of seizures induced, and (3) the severity of each seizure. Behavioral changes were scored according to the Racine scale, with $0=$ normal activity; $1=$ hypoactivity; 2 = head or forelimb clonus; $3=$ whole-body clonus, rearing and falling, or wild running; $4=$ tonic-clonic seizures; and $5=$ death (Racine, 1972; Ferraro et al., 1999). EEG recordings were analyzed for latency to onset and number of seizures.

\section{Tissue harvest}

Animals were killed at the end of each experiment and brain tissue was collected through one of two methods. For the first method, one hemisphere was frozen for biochemical analyses and the other hemisphere was immersion fixed for $48 \mathrm{~h}$ at $4^{\circ} \mathrm{C}$ in $4 \%$ paraformaldehyde/1× PBS. For the second method, mice were transcardially perfused with PBS containing $10 \mathrm{U} / \mathrm{ml}$ heparin followed by $4 \%$ paraformaldehyde/1× PBS and postfixed for $24 \mathrm{~h}$ at $4^{\circ} \mathrm{C}$ in $4 \%$ paraformaldehyde/1× PBS.

\section{Immunoblotting}

Frozen hemi-forebrain or cortical tissue was homogenized by sonication in 7.5 volumes of $2 \%$ SDS and then diluted with an equal volume of $2 \times$-concentrated RIPA buffer minus SDS $(2 \times$ PBS, $1 \%$ deoxycholate, $1 \%$ NP40, 5 mM EDTA, plus protease inhibitors) to yield a $6.7 \%$ homogenate in $1 \times$ RIPA buffer. Approximately $35 \mu \mathrm{g}$ of protein from this homogenate was separated using $10.5-14 \%$ Tris-glycine gels (Bio-Rad) for quantitation of protein levels. After transfer to nitrocellulose (iBlot; Invitrogen), blots were blocked for $1 \mathrm{~h}$ in $5 \%$ nonfat dry milk before being incubated with one or more primary antibodies: mouse antihuman APP/A $\beta$ antibody 6E10 (catalog \#9300-02, 1:5000; Signet), rabbit anti-CT15 (1:4000; a gift from Eddie Koo). Chicken anti-GAPDH polyclonal antibody (catalog \#Ab2302, 1:5000; Millipore) was used as a loading control. Binding was detected with HRP-labeled secondary antibodies and developed with ECL reagent (Millipore). Chemiluminescence was measured with a Fuji LAS-4000 mini CCD system and quantified using MultiGauge software.

\section{Histology}

Immersion-fixed hemibrains were cryoprotected with 30\% sucrose at $4^{\circ} \mathrm{C}$ before being frozen and sectioned at $35 \mu \mathrm{m}$ using a freezing sliding microtome. Sections were stored in cryoprotectant at $-20^{\circ} \mathrm{C}$ until use.

Campbell-Switzer silver stain. Amyloid was detected from a 1 in 24 series of sections using the Campbell-Switzer silver stain. A detailed protocol for this stain can be found online at the NeuroScience Associates website (http://www.neuroscienceassociates.com/Documents/Publications/ campbell-switzer_protocol.htm).

$A \beta$ immunohistochemistry. A 1 in 24 series of sections was pretreated with $88 \%$ formic acid for $1 \mathrm{~min}$ at room temperature, rinsed several times with TBS, and blocked with TBS plus $0.1 \%$ Triton-X (TBST) containing $1.5 \%$ normal goat serum before being incubated overnight at $4^{\circ} \mathrm{C}$ with rabbit anti-APP/A $\beta$ antibody diluted in blocking solution (catalog \#44344, 1:500; Zymed). After washing with TBS, sections were incubated for $1 \mathrm{~h}$ with biotin-conjugated goat anti-rabbit secondary antibody (Vectastain Elite Rabbit IgG ABC Kit, 1:500; Vector Laboratories), followed 
by HRP-avidin conjugate diluted 1:100 in TBS for $30 \mathrm{~min}$, and then developed with DAB.

Vesicular glutamate transporter 1/vesicular GABA transporter immunofluorescence. Sections were rinsed with TBS to remove antifreeze and blocked with TBS plus $0.1 \%$ Triton X-100 containing 5\% normal goat serum followed by overnight incubation at $4^{\circ} \mathrm{C}$ in primary antibody diluted in blocking solution (rabbit antivesicular glutamate transporter 1 [vGLUT1], catalog \#135-303, 1:2000; Synaptic Systems and guinea pig antivesicular GABA transporter [vGAT], catalog \#131-004, 1:750; Synaptic Systems). After washes with TBS, sections were incubated with Alexa Fluor 488-conjugated goat anti-rabbit antibody (catalog \#A11034, 1:500; Invitrogen) and Alexa Fluor 594-conjugated goat anti-guinea pig antibodies (catalog \#A11076, 1:750; Invitrogen).

Quantification of $v G L U T 1 / v G A T$. Sagittal sections located $\sim 1-1.5 \mathrm{~mm}$ from midline were selected for analysis based on landmarks in hippocampus, lateral ventricle, and striatum. A total of 4-5 sections were imaged per animal. Fluorescent images were collected from nonoverlapping fields within cortex (L2/3 above CA1 and L5 above lateral ventricle). A single optical plane of $0.977 \mu \mathrm{m}$ in depth was collected in red (vGAT) and green (vGLUT) channels using an ApoTome structured illumination device (Carl Zeiss) at $40 \times$ magnification $(222.2 \times 166.4 \mu \mathrm{m}$ per field). We used a custom script written in MATLAB (R2012b) to batch process two-channel fluorescence images in an unbiased and automated way. Grayscale images were binarized using Otsu's method to divide the dataset into signal and background so that the variance in each of the resulting subsets is mimimized. In this case, the method uses variance minimization to define the cutoff between immunopositive pixels and background. The script then calculates the area occupied by vGLUT- or vGAT-positive pixels in each image normalized to the total area of the field. We have posted a modified version of the script on MATLAB's file exchange site (http://www.mathworks.com/matlabcentral/fileexchange/ 39591).

\section{Statistics}

EEG power, entropy, and autocorrelation analyses were analyzed by repeated-measures ANOVA using MATLAB; reported $p$-values represent the main effect of genotype. All other statistical analyses were done using GraphPad Prism 5.0. Comparisons between two groups were analyzed using Student's $t$ test. Comparisons involving more than two groups were analyzed using one-way or two-way ANOVA followed by Bonferroni post hoc tests. Unless indicated (and with the exception of power, entropy, and autocorrelation analyses), all reported $p$-values are for post hoc comparisons. All graphs display group mean \pm SEM.

\section{Results \\ Tet-off APP mice display EEG abnormalities similar to other APP-transgenic models}

A growing number of studies have documented abnormal electrical activity in APP-transgenic models for Alzheimer's disease (Lalonde et al., 2005; Palop et al., 2007; Westmark et al., 2008; Minkeviciene et al., 2009; Ziyatdinova et al., 2011; Sanchez et al., 2012; Verret et al., 2012; Corbett et al., 2013). These models differ in the APP mutations they encode, the coexpressed transgenes, and the promoters used to drive expression. We were therefore optimistic that their shared APP overexpression is salient to the EEG phenotype and that we might also find EEG abnormalities in our tetracycline-controllable APP-transgenic mice. These mice express mouse APP with a humanized $\mathrm{A} \beta$ domain harboring the Swedish and Indiana familial mutations (tetO-APP line 102) under control of the CaMKII $\alpha$-TTA driver (APP/TTA; Jankowsky et al., 2005). We used traditional wire-lead EEG recordings (Stellate Systems) to measure electrical activity in the brains of bigenic APP/TTA animals and their single-transgenic and NTG siblings at an age when we knew the bigenic mice would harbor amyloid pathology (7-9 months). As described for other APP-transgenic models, we detected frequent SWDs and irregular seizure episodes in the APP/TTA mice (19/21 exhibit >30 SWDs/h), whereas both of these features were absent from traces recorded in controls (0/15 mice exhibit $>30$ SWDs/h; Fig. 1$)$.

Although wired EEG recordings are the gold standard for localizing the origin and spread of seizure activity, our system was limited in throughput. To conduct a quantitative analysis of EEG abnormalities in our model and then follow their response to various interventions, we moved to a wireless radiofrequency telemetry system that enabled us to perform continuous homecage EEG recordings from up to eight mice at a time. Consistent with the qualitative observation from wired EEG recordings, quantitative analysis of wireless telemetry sessions confirmed that APP/TTA mice display a significantly higher number of SWDs/h than age-matched NTG and TTA controls $(\mathrm{NTG}=$ $6.24 \pm 0.62 ; \mathrm{TTA}=7.84 \pm 1.12, \mathrm{APP} / \mathrm{TTA}=125.40 \pm 16.62$, $p<0.001, n=4-11$ mice/genotype; Fig. 1). We found no differences in the EEG properties of NTG and TTA mice and decided to combine both genotypes into balanced control groups for subsequent experiments.

We also assessed locomotor activity during our EEG sessions using information collected by the telemetry device. We found an inverse correlation between SWD frequency and ambulation such that SWD frequency was highest during daylight hours, when the mice are the least physically active and more likely to be asleep (Fig. 1).

\section{Genetic suppression of transgenic APP normalizes cortical EEG activity}

One advantage of using the tet-off APP model is that we can exercise temporal control over transgenic APP expression using orally administered DOX. Transgene expression can be reduced by $>90 \%$ using moderate doses of DOX compounded into the chow (Jankowsky et al., 2005; Wang et al., 2011; Rodgers et al., 2012). In the present experiments, chow provided by a different vendor was slightly less effective but still reduced transgenic APP levels by $\sim 80 \%$. Transgenic APP was reduced by $77 \pm 0.09 \%$ within $2 \mathrm{~d}$ of DOX administration and remained at $82 \pm 0.02 \%$ suppression 4 weeks later ( $n=3-5$ mice/time point; Fig. 2$)$. We next performed in vivo microdialysis of hippocampal interstitial fluid to confirm that $\mathrm{A} \beta$ levels declined in parallel with transgenic APP expression. Baseline levels of $A \beta 40$ and $A \beta 42$ were $231.1 \pm 30.1 \mathrm{pg} / \mathrm{ml}$ and $25.42 \pm 3.7 \mathrm{pg} / \mathrm{ml}$, respectively $(n=5)$, but dropped by nearly half to $48.0 \pm 5.4 \%(\mathrm{~A} \beta 40)$ and $55.6 \pm 5.3 \%(\mathrm{~A} \beta 42)$ within $2 \mathrm{~d}$ after the mice began DOX treatment (Fig. 2). We suspect that compensatory release of exchangeable $A \beta$ from nearby amyloid plaques may have limited the reduction of interstitial $A \beta$ relative to full-length APP (Hong et al., 2011). Nonetheless, both transgenic APP and transgene-derived $A \beta$ were significantly decreased within $2 \mathrm{~d}$ of DOX treatment. Despite the significant reduction in $\mathrm{A} \beta$ release, amyloid load was unchanged by DOX treatment. We have used this model in past studies to demonstrate that transgene suppression arrests amyloid growth indefinitely (Jankowsky et al., 2005; Wang et al., 2011). Plaque load neither progresses nor abates, so DOX treatment provides a way of reducing transgenic APP and soluble/exchangeable forms of $\mathrm{A} \beta$ without altering deposited amyloid.

Once baseline EEG recordings were completed, we switched all of the mice to DOX chow and continued weekly EEG recordings for another $4-5$ weeks (Fig. 2). We found that SWD frequency steadily decreased in the APP/TTA mice, but over a time frame considerably longer than that of transgene suppression. After 2 weeks of DOX treatment, the SWD frequency in APP/TTA mice was significantly lower than baseline 
A

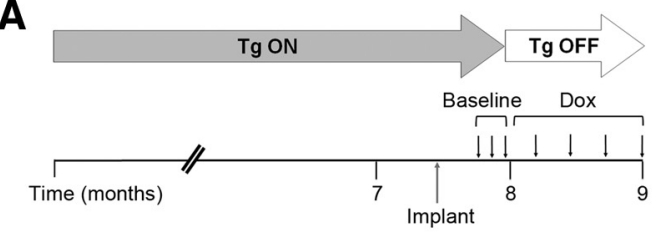

G TTA: Baseline

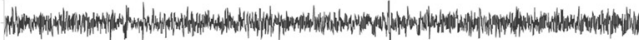

TTA: 4 wk Dox

How

APP/TTA: Baseline

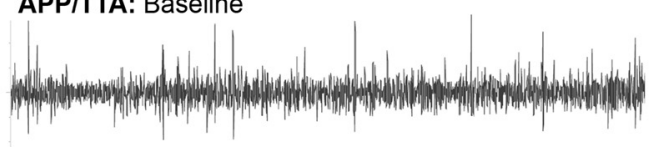

APP/TTA: 4 wk Dox

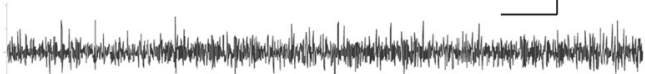

H

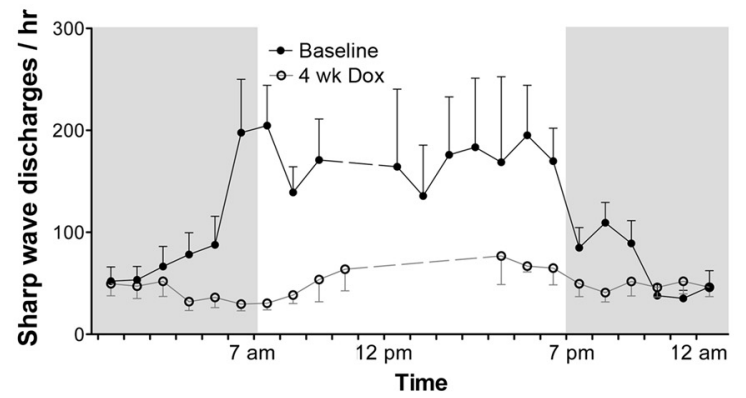

J

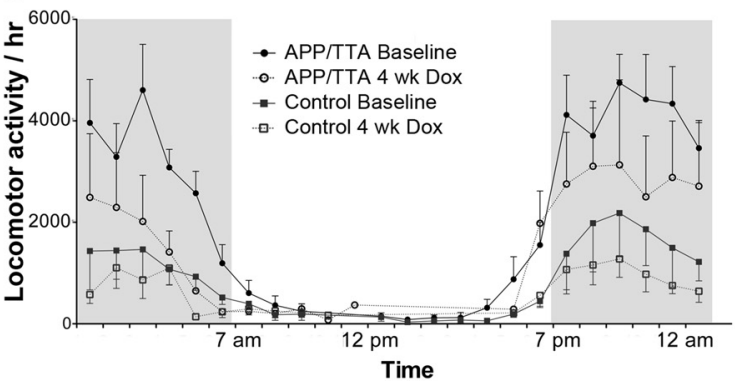

B

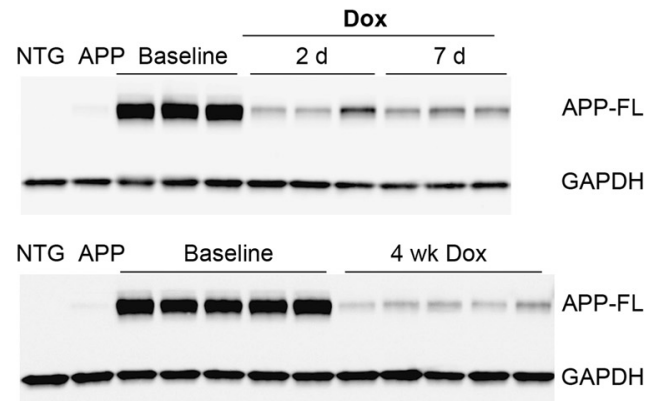

E
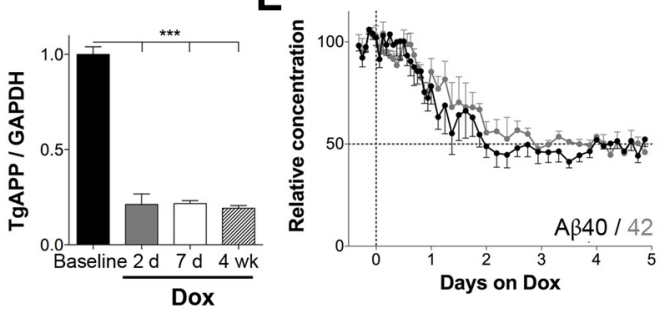

$\mathbf{F}$
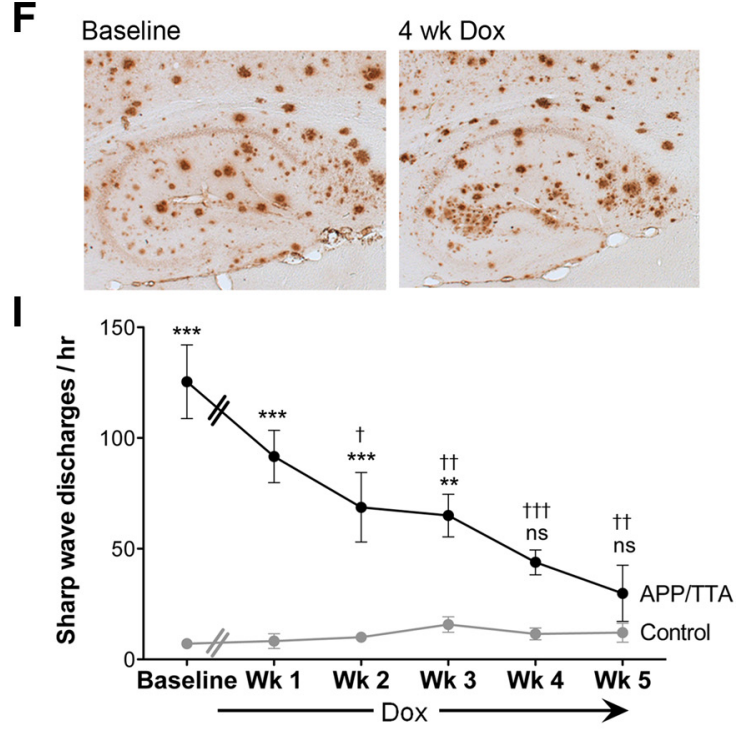

Figure 2. Transgene suppression reduces the frequency of SWDs in APP/TTA mice. A, Mice were implanted with radiofrequency transmitters at $7-8$ months of age. After baseline recordings were completed, all mice were treated with DOX while continuing weekly EEG recordings. B, C, Western blotting for transgenic APP (6E10) confirmed that untreated APP/TTA mice expressed high levels of transgenic protein. Expression was substantially decreased within $2 \mathrm{~d}$ of DOX treatment and remained low at the end of the experiment $4-5$ weeks later. $D$, Quantification of the Western blots shown in $\boldsymbol{B}$ and $\boldsymbol{C}$. Transgenic APP has been normalized to GAPDH and all values are expressed relative to baseline expression in untreated bigenic animals. ${ }^{* * *} p<0.001$. $\boldsymbol{E}$, In vivo microdialysis showed that ISF $A \beta$ reached new steady-state levels within days after transgene suppression. Black circles, $A \beta 40$; gray circles, $A \beta 42 . F$, Tissue sections immunostained for $A \beta$ confirmed that plaque loads were similar in untreated and DOX-treated APP/TTA mice used for EEG analysis. G, EEG abnormalities in APP/TTA mice were substantially reduced after 4 weeks of transgene suppression. Scale bar, $0.4 \mathrm{mV}, 5 \mathrm{~s}$. H, Comparison of SWD frequency over time in APP/TTA mice before and after 4 weeks of transgene suppression revealed that the decrease in SWD frequency was most pronounced during daylight hours. Filled circles, baseline; open circles, DOX 4 weeks. I, Rate of SWDs in APP/TTA mice declined steadily from the start of treatment and became statistically indistinguishable from controls after 4 weeks of transgene suppression. Black circles, APP/TTA; gray circles, Control. ${ }^{* *} p<0.01$, ${ }^{* * *} p<0.001$ vs Control; $\uparrow p<0.05,+\dagger p<0.01,+t+p<0.001$ vs Baseline. J, Locomotor activity measured during EEG recordings suggests that nighttime movement is slightly diminished in both genotypes by DOX treatment. Circles, APP/TTA; squares, Control; filled symbols, Baseline; open symbols, DOX 4 weeks. 
(baseline: $125.4 \pm$ 16.6; DOX 2 weeks: $68.7 \pm 15.6$ SWDs/h; $p<0.05 ; n=11$ mice). After 4 weeks of DOX treatment, the frequency of SWD in APP/TTA mice was statistically indistinguishable from controls (DOX 4 weeks, APP/TTA: $43.9 \pm 5.6$; Control: $11.5 \pm 2.7$ SWDs/h; DOX 5 weeks, APP/TTA: $29.9 \pm 12.7$; Control: $12.1 \pm 4.3$ SWDs/h, $p>0.05$, $n=9-11$ mice/genotype). The change was most apparent during daylight hours, when SWD frequency was highest in the untreated mice. In contrast, the rate of SWDs in our control group (a balanced mix of NTG and TTA) was already low at baseline and did not change with DOX treatment.

The presence of SWDs is just one feature of the EEG signal that distinguishes APP-transgenic mice from controls. Past studies have shown significant irregularities in the power spectrum of EEG signals from APP-transgenic animals, noting that a subset of mice display dramatic changes in amplitude at selected wavelengths (Verret et al., 2012). We were particularly keen to determine whether similar differences existed in the APP/TTA mice and, if so, whether they were normalized by transgene suppression. We examined three features of the EEG signals that broadly defined their underlying structure: (1) the power spectrum across wavelengths, (2) the entropy of interpeak intervals, and (3) signal autocorrelation. In agreement with past studies, we found that the power spectrum differed significantly between genotypes during baseline recordings. Power curves from APP/TTA and control mice were readily distinguished by their profiles and their peaks. Although control animals displayed peak power levels in the delta range $(2.6-3.8 \mathrm{~Hz}$, peak at 3.1, $n=8)$, the spectra of APP/TTA mice reached maximal power at frequencies in the theta range $(5.9-8.5 \mathrm{~Hz}$, peak at $7.6 ; n=10)$ and the overall distribution of the two groups was significantly different $(p=0.014$, Fig. 3$)$. In contrast, the power spectra after DOX treatment were nearly indistinguishable $(p=0.62)$. Both groups had peak power levels in the delta to low theta range (Control: 2.2-6.8 Hz, APP/TTA: 2.6-6.8 Hz). Transgene suppression thus rebalanced the power of the EEG signal across the entire range of frequencies.

EEG signals reveal a continuous ebb and flow of neuronal activity that occurs at a level far below overt SWD. The amplitude of "chatter" in the signal rises and falls hundreds or thousands of times each minute in both healthy controls and transgenic animals. Under normal conditions, these movements approximate random variation with little or no periodicity to the signal. This characteristic is mathematically defined by its entropy. EEG signals with regular, repeating patterns have lower entropy than signals that vary randomly, reflecting a higher degree of rhythmic synchronization in the network. Consistent with this characterblue, Control.
UNTREATED
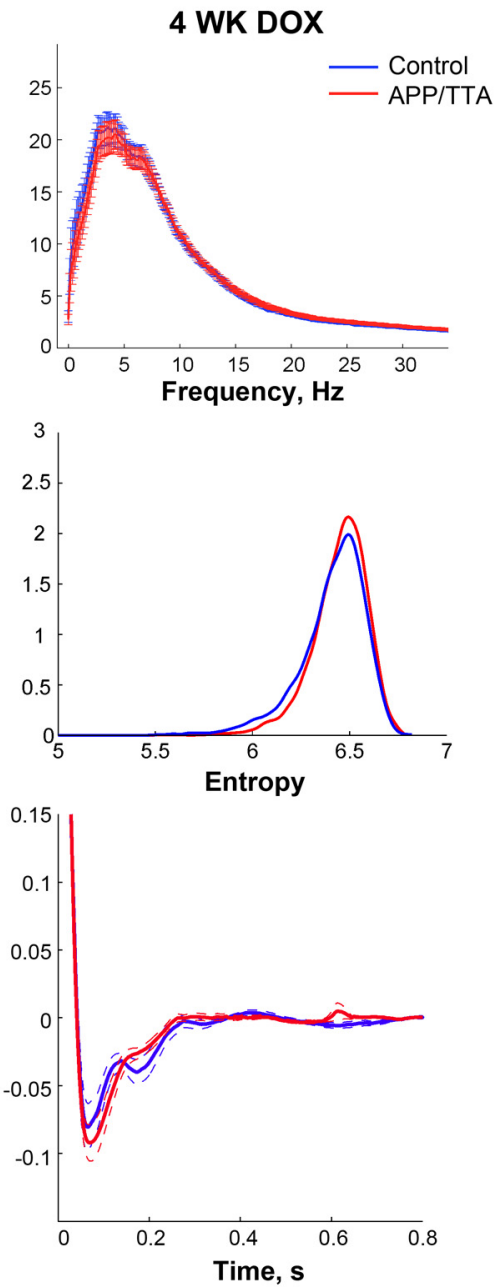

Figure 3. Transgene suppression normalizes the power spectrum, entropy, and autocorrelation of EEG signal in APP/TTA mice. $A$, Spectral analysis of the EEG signal revealed a shift toward higher power in the theta range and diminished power in the delta range of untreated APP/TA mice compared with controls. After 4 weeks of transgene suppression, the power distribution was control mice, suggesting that their electrical activity is less stochastic than normal. The entropy distribution returns to control levels after 4 weeks of transgene suppression. C, Autocorrelation within the EEG signal is lower in untreated APP/TTA mice than controls, indicating that the signal is intrinsically more structured. This, too, returns to control levels after DOX treatment. Red, APP/TTA;

ization, we found that the entropy of peak timing in baseline recordings from APP/TTA was significantly lower than in control mice. Although the absolute numbers are immaterial (they vary with the peak threshold and time window used to measure interpeak intervals), the overall shape of the entropy probability distribution for untreated APP/TTA mice was much lower and broader than the corresponding control values $(p=0.033$; Fig. 3). This finding was supported by characterization of autocorrelation in the signal, which provides another way of detecting regular structure in complex data. At short time lags, the signal from untreated APP/TTA mice showed a greater degree of negative autocorrelation than controls $(p=0.021$; Fig. 3). In other words, the EEG amplitude could be more predictably expected to increase within 50-100 ms after it had fallen (and vice versa) in APP/TTA mice than in controls. However, both entropy and autocorrelation returned to control levels after 4 weeks of transgene suppression $(p=0.48$ and $p=0.32$, respectively). These findings indicate that the EEG abnormalities observed in untreated APP/TTA mice were de- 
A

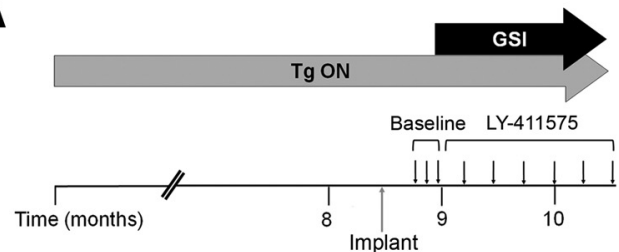

\section{B}

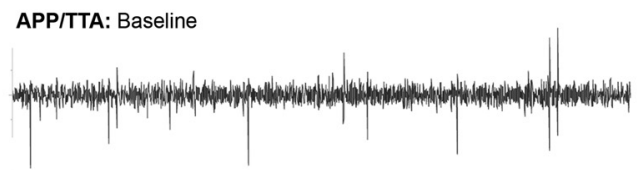

APP/TTA: 1 wk GSI

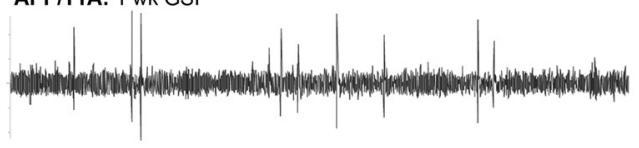

APP/TTA: 4 wk GSI

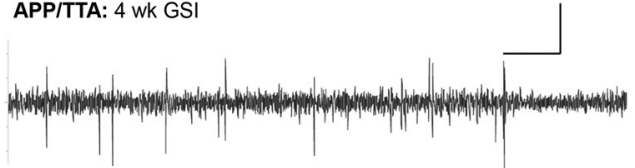

C

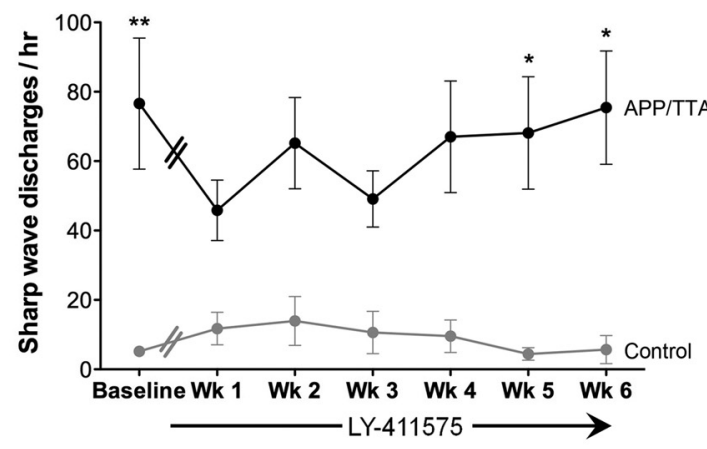

D

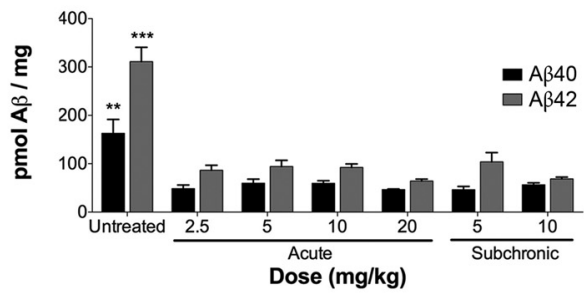

$\mathbf{E}$

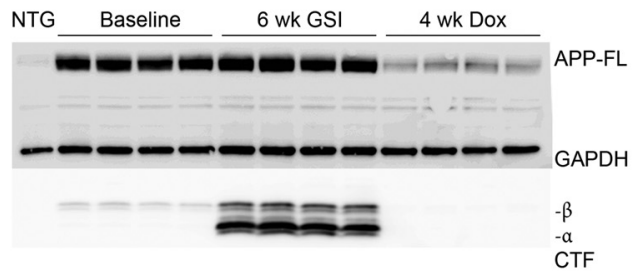

$\mathbf{F}$

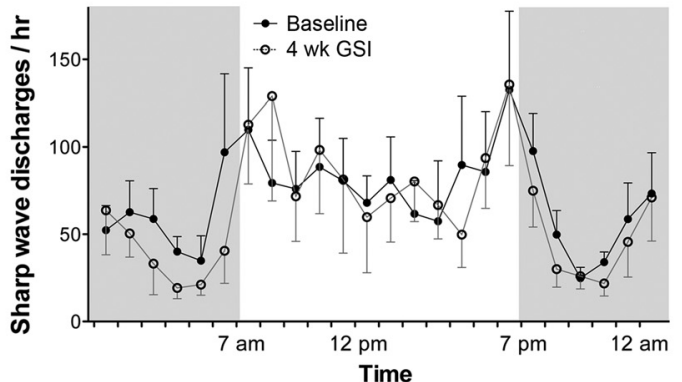

G

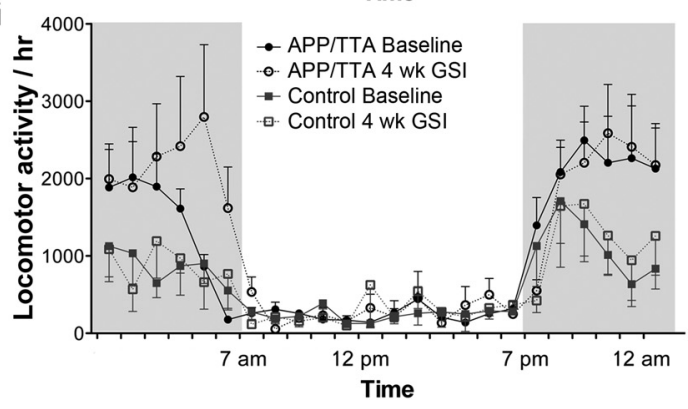

Figure 4. Selective A $\beta$ reduction does not diminish SWD frequency in APP/TTA mice. A, Mice were implanted at $8-9$ months for baseline EEG recordings before GSI treatment with continued weekly recordings. $B$, EEG recordings made before and during GSI treatment show that SWDs in APP/TTA mice were unchanged after 4 weeks of selective A $\beta$ reduction. Scale bar, $0.4 \mathrm{mV}, 5 \mathrm{~s}$. $C$, EEG analysis confirmed that the rate of SWDs in APP/TTA mice did not change during treatment and remained statistically different from controls after 6 weeks of GSI treatment. Black, APP/TTA; gray, Controls. ${ }^{*} p<0.05,{ }^{* *} p<0.01,{ }^{* * *} p<0.001$. D, Dose-response analysis for LY411575 in young, predeposit APP/TTA mice revealed that both acute and chronic treatment reduced A $\beta$ levels in the brain. ${ }^{* *} p<0.01,{ }^{* * *} p<0.001$. E, Western blotting with 6 E10 shows that expression of full-length transgenic APP is maintained during GSI treatment, however, the levels of C-terminal fragment (CTF) increase as expected after $\gamma$-secretase inhibition. $\boldsymbol{F}$, Analysis of SWD frequency over time reveals that the circadian pattern of EEG activity in APP/TTA mice was unchanged by GSI treatment. Filled circles, Baseline; open circles, GSI 4 weeks. G, Locomotor hyperactivity was also unchanged by GSI treatment. Circles, APP/TTA; squares, Control; filled symbols, Baseline; open symbols, GSI 4 weeks.

pendent on continued expression of transgenic APP, but were independent of deposited amyloid.

\section{$\gamma$-Secretase inhibitor treatment does not rescue EEG abnormalities in tet-off APP mice}

The rescue of EEG abnormalities by transgene suppression suggested that either APP itself or one of its cleavage products was responsible for establishing aberrant hyperexcitability in our tetoff APP mice. Based on its proposed role in Alzheimer's disease, we initially suspected that $A \beta$ provoked this cortical hyperactivity. To test whether reducing $A \beta$ would be sufficient to attenuate EEG abnormalities, we treated mice with a potent $\gamma$-secretase inhibitor (GSI), LY411575, which selectively decreased A $\beta$ production without affecting full-length APP expression. We first measured the dose-response curve for this drug using brain $\mathrm{A} \beta$ levels as a readout of efficacy. We treated predeposit APP/TTA mice ( 5 weeks of age, $n=4-6$ per dose) with a single intraperitoneal injection of $0,2.5,5,10$, or $20 \mathrm{mg} / \mathrm{kg}$ and harvested $3-4 \mathrm{~h}$ later. A second group of mice was chronically treated for 1 week by compounding the drug into chow at concentrations that would deliver 5 or $10 \mathrm{mg} / \mathrm{kg} / \mathrm{d}$ orally. The reduction in steadystate $A \beta$ levels attained by acute dosing suggested that maximal efficacy was reached by $2.5 \mathrm{mg} / \mathrm{kg}$; however, the $\mathrm{A} \beta$ levels measured after 1 week of chronic treatment suggested that $10 \mathrm{mg} /$ $\mathrm{kg} / \mathrm{d}$ achieved slightly better reduction for $\mathrm{A} \beta 42$ than $5 \mathrm{mg} / \mathrm{kg} / \mathrm{d}$ (Fig. 4).

With information gained from this initial dosing study, we began baseline EEG recordings in a new cohort of 8- to 9-monthold mice before beginning treatment with LY411575. We treated the mice with chow formulated to provide $10 \mathrm{mg} / \mathrm{kg} / \mathrm{d}$ for the first 2 weeks of treatment, followed by $5 \mathrm{mg} / \mathrm{kg} / \mathrm{d}$ to reduce mortality for an additional 4 weeks. To our surprise, we found no apparent 
differences in SWD frequency during GSI treatment. Unlike what we had observed after transgene suppression, the number of SWDs/h remained stable in GSI-treated APP/TTA mice over successive weeks of recording ( $p>0.05, n=8-10$; Fig. 4 ). Neither the circadian pattern of SWDs nor locomotor hyperactivity was altered after 4 weeks of GSI treatment. Even after 6 weeks of GSI treatment, SWD frequency remained identical to baseline $(p>0.05$, Student's $t$ test). Similarly, sibling controls showed no difference from baseline throughout the 6 week GSI treatment ( $p>0.05, n=3-6 /$ time point). During treatment, all of the mice developed side effects characteristic of GSI treatment, including changes in pigmentation and patchy hair loss. After harvesting the mice, we confirmed that the dose of GSI we used was adequate to dramatically increase APP C-terminal fragments, suggesting that it had reached therapeutic levels in the brain. We conclude that GSI was sufficient to significantly reduce $\mathrm{A} \beta$ production, but failed to rescue EEG abnormalities and locomotor hyperactivity. Contrary to our initial expectations, these data suggest that APP itself or a fragment other than $A \beta$ is responsible for EEG abnormalities in the tet-off APP mice.

\section{Overproduction of $\mathrm{A} \boldsymbol{\beta}$ is not sufficient to generate EEG abnormalities in double knock-in APP/PS1 mice}

As a counterpoint to GSI treatment, which selectively suppresses $\mathrm{A} \beta$ overproduction while maintaining APP overexpression, we recorded EEGs from mice that have elevated levels of $A \beta$ with endogenous levels of APP expression. We implanted EEG transmitters in homozygous $\mathrm{APP}_{\text {Swe/Lon }} / \mathrm{PS}_{\mathrm{M} 146 \mathrm{~V}}$ double knock-in (DKI) mice and their WT siblings at 23-24 months of age and recorded EEG activity during 7 sessions over 2 weeks (Fig. 5). This model displays early behavioral alterations (2-3 months) but fairly late amyloid deposition, with initial plaques apparent between 18 and 22 months of age (Guo et al., 2012; Guo et al., 2013). Although we recorded twice as many baseline sessions for the DKI mice as we had for the tet-off APP mice, we observed no EEG abnormalities and no increase in SWD frequency from controls $(\mathrm{WT}=1.18 \pm 0.17 ; \mathrm{DKI}=2.34 \pm 0.69 \mathrm{SWDs} / \mathrm{h}, p>0.05$, Student's $t$ test with Welch's correction, $n=4-5$ /genotype). We harvested the mice after recording to ascertain the presence of amyloid pathology expected from this model by 24 months of age. Although the plaque burden was considerably lower than in the tet-off APP mice, silver-positive plaques were detected in the hippocampus and cortex of all DKI mice we examined. This suggests that, in the absence of APP overexpression, $A \beta$ overproduction is not sufficient to alter network excitability and lends further support to the hypothesis that full-length APP or another cleavage fragment underlies EEG abnormalities in the tet-off APP animals.

Increased susceptibility to chemically induced seizures is not attenuated by diminishing spontaneous hyperactivity

Because the tet-off APP mice exhibit spontaneous EEG abnormalities, we wanted to test whether they were also more vulnerable to chemically induced seizures, as demonstrated for other APPtransgenic models (Del Vecchio et al., 2004; Palop et al., 2007;
Westmark et al., 2008). We implanted APP/TTA and control animals with transmitters at 6-7 months of age to monitor the seizure induction both electrographically and behaviorally. We measured the time to seizure onset, the number of seizures evoked, and the behavioral severity using a modified Racine scale (Racine, 1972; Ferraro et al., 1999). We began by testing susceptibility to the noncompetitive $\mathrm{GABA}_{\mathrm{A}}$ antagonist picrotoxin, which has a similar mechanism of action as pentylenetetrazol, the agent most commonly used in past studies with APP-transgenic mice. We determined that $1.75 \mathrm{mg} / \mathrm{kg}$ subcutaneously was just below the threshold for convulsive seizures in NTG animals, so we used this dose for EEG/behavioral studies in APP/TTA mice. The APP/TTA mice showed a significantly stronger response to picrotoxin than control animals for all measures we evaluated ( $p<0.05$, Student's $t$ test, $n=6$ mice/genotype; Fig. 6). Control animals developed modest EEG abnormalities in response to picrotoxin, but no electrographic seizures and only mild behavioral effects such as a flattened posture or prolonged immobility. In contrast, all of the APP/TTA mice progressed to tonic-clonic seizures within an hour, suggesting that they have an impairment in GABAergic inhibition.

We then tested whether this heightened susceptibility extended to other convulsants with different mechanisms of action. We selected kainic acid as a well studied agonist of ionotropic glutamate receptors and a good counterpoint to our experiments with picrotoxin. We determined that $35 \mathrm{mg} / \mathrm{kg}$ was just below the convulsive dose for kainic acid in NTG controls. To our surprise, APP/TTA transgenic animals were no more susceptible to kainic acid than controls ( $p>0.05$, Student's $t$ test, $n=5$ mice/genotype; Fig. 6). Kainate induced electrographic and behavioral seizures in some, but not all, mice of both genotypes. These data demonstrate that spontaneous electrographic hyperactivity does not automatically predispose the network to chemically induced seizures and suggests that the two neurotransmitter systems may be differentially altered by APP overexpression.

We were next curious to test whether allaying spontaneous EEG abnormalities in the tet-off APP mice would normalize their susceptibility to picrotoxin. We treated 6-month-old APP/TTA mice with DOX for 5 weeks before implanting them with transmitters and challenging them with picrotoxin. Despite the expected decline in SWD frequency, the DOX-treated APP/TTA mice were still significantly more susceptible to picrotoxin than 
A
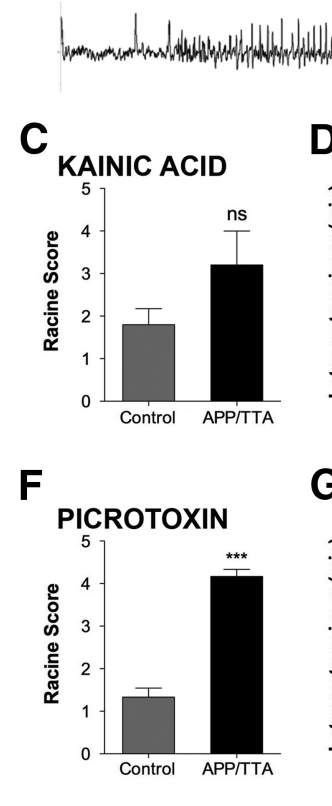

I DOX + PICROTOXIN

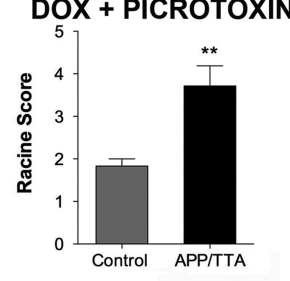

B

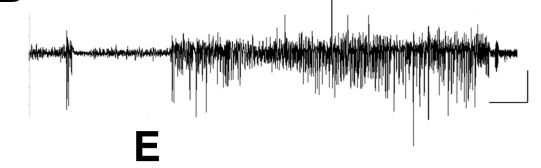

E

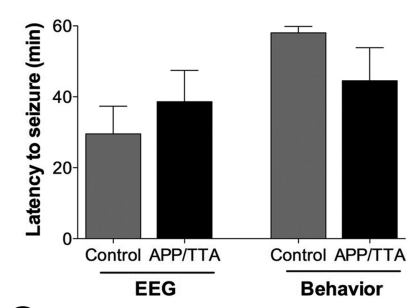

G

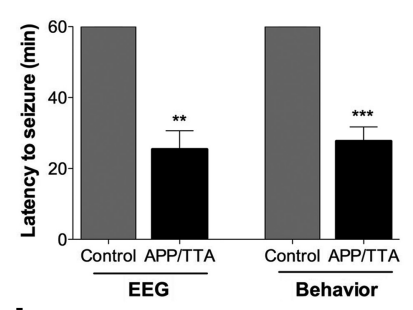

J

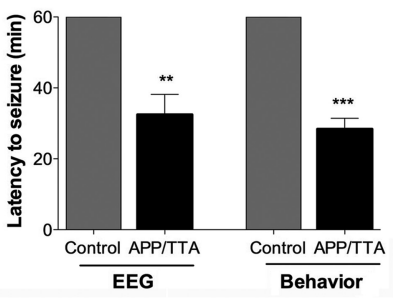

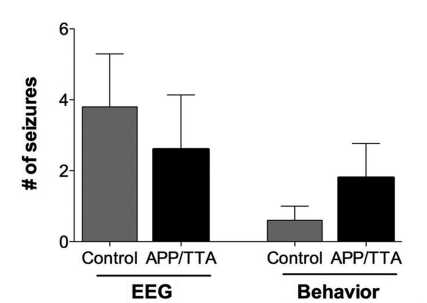

$\mathbf{H}$

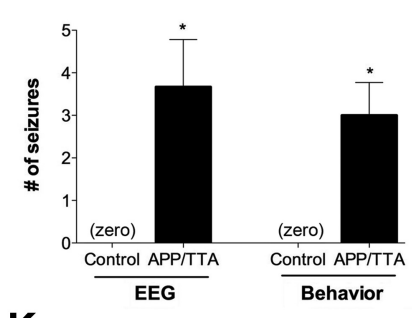

K

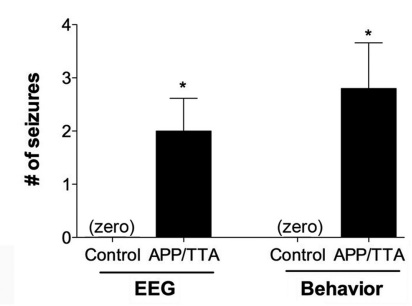

Figure 6. APP/TTA and control mice were challenged with kainic acid $(A, C, D, E)$ or picrotoxin $(B, F, G, H)$ and scored for seizure induction by EEG and behavioral observation. A separate cohort was treated with DOX for 5 weeks before picrotoxin challenge (I-K). $\boldsymbol{A}, \boldsymbol{B}$, Example EEG traces from APP/TTA mice challenged with kainic acid or picrotoxin. Scale bars: $\boldsymbol{A}, 0.4 \mathrm{mV}, 1 \mathrm{~s} ; \boldsymbol{B}, 0.4 \mathrm{mV}$, 5s. $C, F, I$, Seizure severity was scored using a modified Racine scale. $\boldsymbol{D}, \boldsymbol{G}, \boldsymbol{J}$, Latency to first seizure. $\boldsymbol{E}, \boldsymbol{H}, \boldsymbol{K}$, Total number of seizures observed in the first hour after drug challenge. ${ }^{*} p<0.05,{ }^{* *} p<0.01,{ }^{* * *} p<0.001$.

similarly treated controls by every metric we tested $(p<0.05$, Student's $t$ test, $n=5-7$ mice/genotype). These data suggest that increased sensitivity to acute GABA inhibition is mechanistically distinct from spontaneous SWDs and that cellular changes that diminish the likelihood of spontaneous SWDs are insufficient to protect against induced seizure.

\section{APP overexpression alters the excitatory to inhibitory balance} in the cortex

The sensitivity of APP/TTA mice to both spontaneous SWDs and acute GABAergic inhibition prompted us to test whether there may be underlying changes in the excitatory to inhibitory balance. We examined the relative levels of glutamatergic to GABAergic innervation by measuring the density of synaptic immunostaining for their respective vesicular neurotransmitter transporters, vGLUT and vGAT. Because our EEG recordings were taken above parietal cortex, we focused our histological analyses on this region and specifically on the main neuronal cell body layers $2 / 3$ and 5 . Within layer 5 , the area occupied by vGLUT staining was significantly lower in APP/ TTA mice than in controls ( $p<0.05 ; n=4-5$ mice/group; Fig. 7 ). vGLUT density was restored to control levels by $4-5$ weeks of transgene suppression, but was not rescued by GSI treatment, which is consistent with our EEG findings. In contrast, vGLUT staining within layer $2 / 3$ was not significantly altered by transgene expression or treatment.

Changes in vGAT staining were opposite to those in vGLUT. In layer 5, the area of vGAT staining increased with APP overexpression ( $p<0.01$ vs control) but decreased to control levels after transgene suppression. vGAT staining in layer $2 / 3$ showed a similar pattern: although the increase in vGAT with transgene expression was not significant, the drop after suppression was ( $p<0.01$ vs untreated). vGAT levels after GSI treatment fell in between those of untreated and DOXtreated animals, but were not significantly changed from untreated APP/TTA mice.

Together, these analyses revealed that continued overexpression of APP caused a significant reduction in the ratio of vGLUT:vGAT within layer 5 ( $p<$ 0.01 vs control) and a parallel trend in layer $2 / 3$. Transgene suppression restored the excitatory/inhibitory ratio to control levels, whereas GSI treatment did not.

\section{Suppression of APP overexpression during postnatal development delays the onset of EEG abnormalities in APP/ TTA mice}

Our EEG recordings after transgene suppression suggested that spontaneous SWDs were dependent on continued expression of mutant APP, but told us little about how network hyperexcitability arose in the first place. Our past studies with the tet-off mice demonstrated that APP overexpression during postnatal brain development had a lifelong impact on locomotor hyperactivity (Rodgers et al., 2012). To test whether delaying the expression of transgenic APP might also prevent network hyperexcitability, we reared a naive cohort of APP/TTA and control mice on DOX from postnatal day 2 (P2) until P42 to withhold APP overexpression until the brain was fully developed. At 6 weeks of age (P42), the mice were switched to normal chow to activate expression of transgenic APP (Fig. 8). At times ranging from 1 to 9 months later, we implanted the mice with EEG transmitters and recorded baseline cortical activity. We were thus able to compare the appearance of EEG abnormalities in juvenile- and adult-onset mice that were matched for duration of transgenic APP expression. Although the juvenile-onset APP/TTA mice showed higher-than-normal SWD frequency from the earliest ages we could examine ( 3 months), the adult-onset mice displayed no EEG abnormalities after 1, 3, or 6 months of transgene expression. However, by 9 months of APP overexpression, SWD frequency rose dramatically, reaching rates similar to those observed in juvenile-onset animals ( $n=5-11$ mice/treatment/age; Fig. 8 ). Despite the initial protection afforded by delaying APP exposure, these mice ultimately developed EEG abnormalities that were as severe as those in animals exposed to transgenic APP as juveniles. The contrast between the early appearance of SWDs in juvenile-onset mice and the substantial delay of SWDs in adult-onset animals suggests 
A
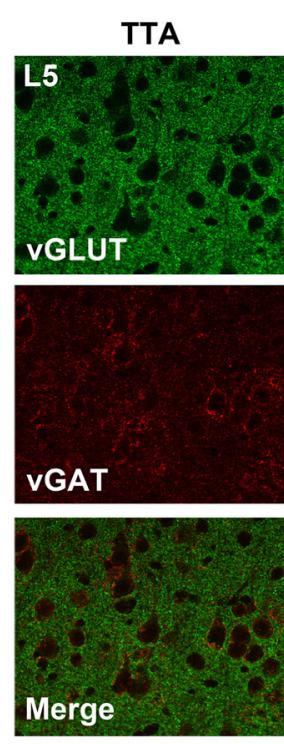

APP/TTA
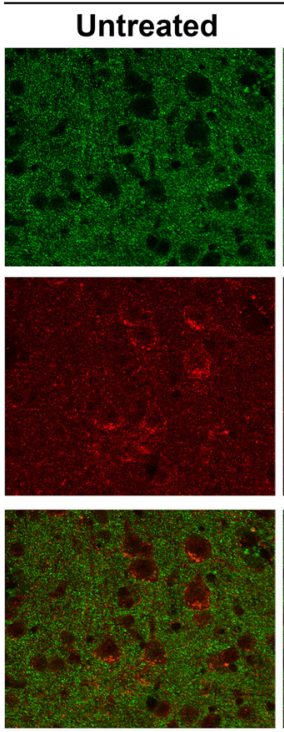

DOX
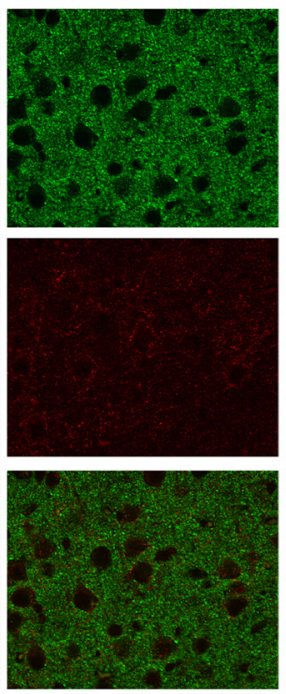

B
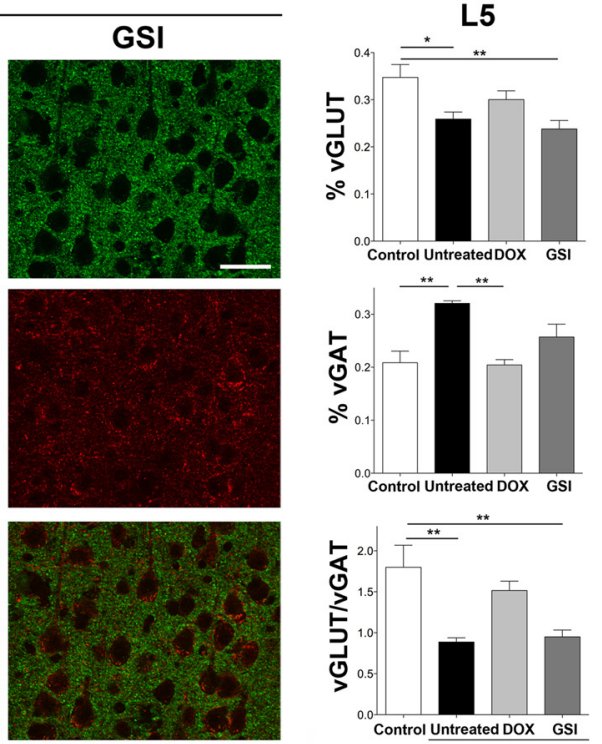

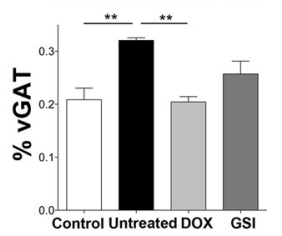

L2/3
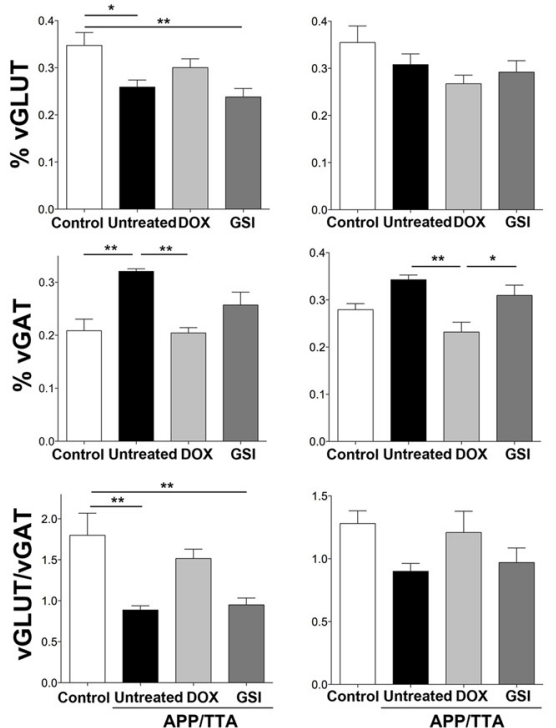

Figure 7. Transgene suppression restores cortical markers of glutamatergic and GABAergic innervation to control levels. $A$, Tissue from TTA and APP/TTA mice used for EEG recording was coimmunostained forvGLUT1 and vGAT. Images show cortex layer 5 from untreated TTA (control) mice along with untreated, DOX-treated, and GSI-treated APP/TTA mice. Scale bar, $50 \mu$ m. B, Percent area occupied by vGLUT1 and vGAT staining within layers $2 / 3$ and 5 was measured using a custom MATLAB script. Untreated APP/TTA mice had a lower density of vGLUT1 and higher density of vGAT in layer 5 than control animals, with a similar trend in layer 2/3. Transgene suppression restored these excitatory/inhibitory markers to control levels, whereas GSI had no effect. ${ }^{*} p<0.05$, ${ }^{* *} p<0.01$.

A
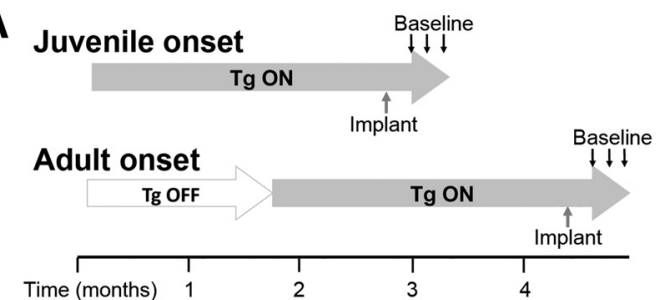

B

APP/TTA: Juvenile onset (6 mo)

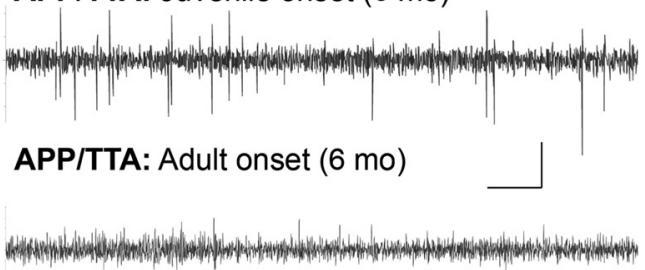

APP/TTA: Adult onset ( $9 \mathrm{mo})$

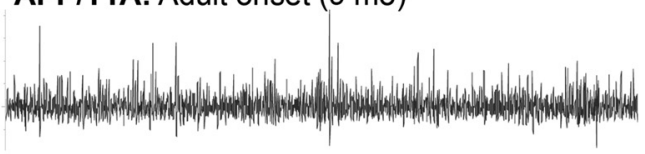

C

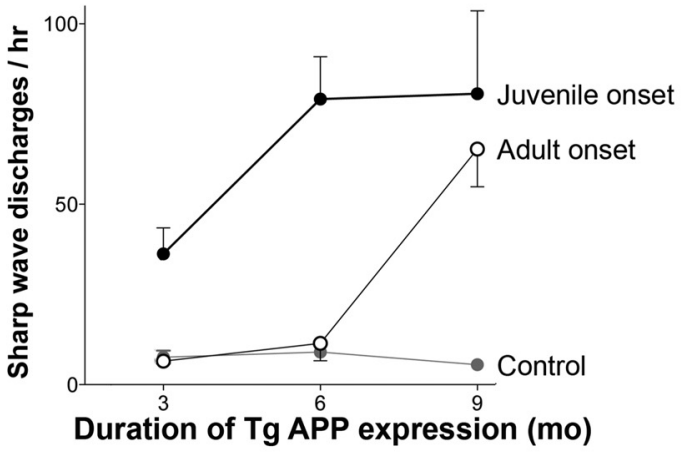

D

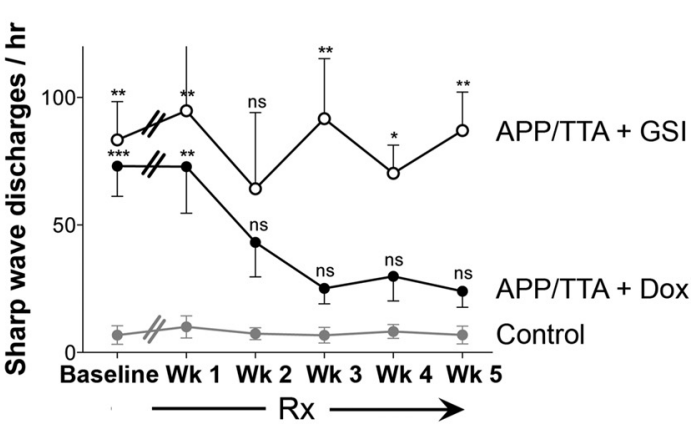

Figure 8. Delaying the onset of APP overexpression protects against early EEG abnormalities. A, EEG activity was compared between juvenile-onset mice that express transgenic APP from birth and adult-onset mice in which APP overexpression was delayed with DOX until the mice reached 6 weeks of age. B, SWDs were common in juvenile-onset APP/TTA mice at both 6 and 9 months of age, but were found in adult-onset mice only after 9 months of APP overexpression. Scale bar, $0.4 \mathrm{mV}, 5 \mathrm{~s}$. C, Transgenic APP expression from birth resulted in elevated SWD frequency by the earliest ages we could examine (3 months), whereas mice with delayed transgene expression develop SWDs considerably later (9 months). Filled circles, juvenile onset; open circles, adult onset. $\boldsymbol{D}$, After 9 months of APP overexpression, adult onset mice were treated either with DOX or with GSI for 5 weeks. The frequency of SWDs decreased to control levels within 2 weeks of transgene suppression, but did not change significantly with secretase inhibition. Filled circles, DOX; open circles, GSI. ${ }^{*} p<0.05,{ }^{* *} p<0.01$.

that postponing transgenic APP expression either provides initial, but not indefinite, protection from mutant APP and its cleavage products or that the two models may reach the same phenotype by distinct mechanisms.
We next examined whether SWDs, once present, were dependent on continued APP overexpression in adult-onset mice, as they had been in mice that expressed APP from birth. After completing baseline EEG recordings in adult-onset mice that had 
overexpressed APP for 9 months, we started DOX treatment and continued weekly recording. We found that SWD frequency decreased to rates that were statistically indistinguishable from controls within 2 weeks of transgene suppression $(p>0.05, n=5-9$ mice/genotype; Fig. 8). We further tested whether selective reduction of soluble $A \beta$ could abate SWDs by treating adult-onset mice with GSI. However, similar to our findings in juvenile-onset mice, GSI treatment had no effect on SWD frequency $(p>0.05$; $n=3$ mice; Fig. 8). This finding suggests that, regardless of when they appear, network changes that support spontaneous SWDs are actively maintained by the continued overexpression of APP rather than by the overproduction of $\mathrm{A} \beta$.

\section{Discussion}

We set out to distinguish whether soluble $\mathrm{A} \beta$, deposited amyloid, or APP itself was responsible for the epileptiform phenotype reported in transgenic models of Alzheimer's disease. In the process, we discovered that the cause of network hyperexcitability was more complex than we expected and was not due directly to either $\mathrm{A} \beta$ or amyloid. We found that juvenile APP overexpression predisposed the adult brain to hypersynchronous discharge. Delaying APP overexpression for just 6 weeks protected against epileptiform activity for $>6$ months, but spontaneous hyperexcitability ultimately emerged as amyloid pathology became severe. Surprisingly, whether epileptiform events were provoked by the development or degeneration, plaques themselves do not appear to govern network activity. Instead, we find that APP itself-or one of its processed fragments-determines the persistence of hyperactivity. Reducing the level of transgenic APP, but not that of $A \beta$, restored network activity to normal even while significant amyloid pathology remained. Phenotypic rescue took longer than was needed to arrest transgene expression, suggesting that APP overexpression elicited network alterations through an indirect mechanism. Consistent with this idea, markers of excitatory and inhibitory innervation revealed an imbalance in the cortical network that supported EEG abnormalities but was restored to normal after APP suppression.

Our study is the first to test directly the proposed link between soluble $A \beta$ species and seizures (Palop and Mucke, 2010). In contrast to what we had expected, diminishing $\mathrm{A} \beta$ with GSI failed to reduce the frequency of SWDs. One concern we had in interpreting these data was that GSI treatment failed to completely eliminate soluble $\mathrm{A} \beta$ from the brain, raising the possibility that the residual $\mathrm{A} \beta$ was sufficient to maintain SWDs. However, transgene suppression was less efficient at lowering soluble $\mathrm{A} \beta$ than GSI yet fully suppressed the SWD phenotype, arguing against this explanation. Instead, our findings suggest that $A \beta$ is not the primary cause of epileptiform discharge in APP-transgenic models. This conclusion is further supported by the absence of EEG abnormalities in aged APP/PS1 knock-in mice with elevated $\mathrm{A} \beta$ production and late-onset plaque formation. Together, these findings suggest that other fragments, or even full-length APP itself, may be responsible for network disruption in APP-transgenic models. APP overexpression might promote network hyperexcitability by exacerbating a physiological function of the endogenous protein, such as neurogenesis, neurite outgrowth, or synapse formation (Zheng and Koo, 2011; Hoe et al., 2012). Endogenous APP expression is highest during synaptogenesis between 2 and 6 weeks of age (Hoe et al., 2012; Westmark, 2013), a time that may be when the developing network is the most sensitive to APP overexpression. Consistent with this idea, we find that mice exposed to transgenic APP as juveniles developed epileptiform activity much earlier than animals in which APP expression was delayed until adulthood. This result sug- gests that APP overexpression during postnatal development makes the brain more susceptible to hypersynchronous activity in the adult.

Although juvenile APP exposure was sufficient to prime network hyperactivity, continued APP overexpression was necessary to maintain it. Intriguingly, even though transgenic APP was reduced by $80 \%$ within days of DOX treatment, it took several weeks for SWD frequency to fully decline. The temporal disparity suggests that the mechanism supporting spontaneous discharge is not a simple on/off process. Our histological data suggest that APP overexpression alters the pattern of cortical innervation, although it is unclear whether it acts directly on synapse formation during development or indirectly as a consequence of later neuronal hyperactivity. The direction of this shift, toward elevated GABAergic and diminished glutamateric innervation, intuitively contradicts the observed hypersynchronous phenotype; however, past work has shown that increased GABAergic signaling can synchronize neuronal firing in the cortex and trigger epileptiform activity (Cobb et al., 1995; Klaassen et al., 2006). Alternatively, the shift in innervation may be a compensatory attempt to dampen network hyperactivity caused by APP overexpression (Palop et al., 2007). Whether causal or reactive, the levels of GABAergic and glutamatergic innervation returned to control levels once transgenic APP was removed from the system. The level of APP expression may thus act as a rheostat on synaptic balance in the brain.

Although spontaneous discharge eventually subsided after APP suppression, bigenic mice remained susceptible to chemically induced seizures. APP/TTA mice were more sensitive to picrotoxin than controls regardless of whether APP expression was active or not, suggesting that some aspects of the network may remain permanently altered by juvenile APP exposure. Past studies in other APP-transgenic models have identified a similar vulnerability to pentylenetetrazol (Del Vecchio et al., 2004; Palop et al., 2007; Westmark et al., 2008; Roberson et al., 2011). Intriguingly, APP/TTA mice were identical to controls for kainate susceptibility, revealing an unexpected degree of selectivity in seizure sensitivity. Recent work suggests that tonic hyperpolarization of cortical interneurons contribute to network excitability in J20 mice (Verret et al., 2012), whereas other APP-transgenic models display overt degeneration of inhibitory neurons (Ramos et al., 2006; Baglietto-Vargas et al., 2010; Takahashi et al., 2010; Loreth et al., 2012). Together, these results support a permanent reduction in GABAergic function caused by developmental exposure to APP overexpression.

How could it be that some aspects of GABAergic dysfunction remain amenable to APP suppression, whereas other changes were permanent? Our experiments do not speak to this distinction directly, but we may gain insight from comparing the phenotypes that changed with those that did not. Both SWD and the theta/delta imbalance were abated by reducing APP levels, but increased sensitivity to picrotoxin was not. Parvalbumin-positive interneurons have been linked to the spontaneous EEG features in APP-transgenic mice and are believed to drive theta oscillations in the healthy brain (Hangya et al., 2009; Cutsuridis and Hasselmo, 2012; Verret et al., 2012). In contrast, other classes of GABAergic interneurons appear to be involved in synchronous discharge caused by picrotoxin (Hiscock et al., 1996). This raises the possibility that APP exposure may have distinct consequences on different classes of interneurons depending on when the transgene is expressed.

The final experiment of our study demonstrated that the timing of APP expression has a significant impact on the resulting phenotype. We had shown previously that postponing transgenic 
APP expression until 6 weeks of age attenuated locomotor hyperactivity in the adult (Rodgers et al., 2012). Here, we show that postponing transgene expression also delayed the appearance of EEG abnormalities. Ultimately, the adult-onset mice developed SWDs similar to those seen at earlier ages after juvenile APP expression, but only after severe amyloid accumulation. This disparity suggests there may be two ways to reach the same phenotypic outcome. In one case, APP overexpression during postnatal development alters network formation to favor hyperexcitability; in the other, pathological damage degrades the network to a point where it becomes vulnerable to synchronization. In both settings, SWDs only persist as long as APP overexpression continues. We therefore propose a "two-hit" model in which either developmental alterations or pathological damage make cortical circuits permissive for synchrony, but then require APP overexpression to trigger recurrent SWDs. From our experiments, we cannot identify the precise fragment responsible, but our GSI findings rule out $\mathrm{AICD}, \mathrm{P} 3, \mathrm{CTF} \alpha$, and $\mathrm{CTF} \beta$, because all four would be affected by the loss of $\gamma$-processing. Although our data do not speak to the mechanism by which APP overexpression triggers SWDs, past work in other models suggest a possible explanation. In particular, BACE1-null mice display seizure abnormalities similar to those described in APP-transgenic mice (Kobayashi et al., 2008; Hitt et al., 2010; Hu et al., 2010). Moreover, expression of mutant APP on the BACE-null background exacerbates the seizure phenotype (Kobayashi et al., 2008), which suggests that neither SAPP $\beta$ nor CTF $\beta$ contribute to SWDs in APP/TTA mice. Instead, high levels of full-length APP in the transgenic mice may commandeer a disproportionate fraction of the cell's limited BACE pool, thereby reducing its ability to process other substrates critical for neuronal function. BACE normally cleaves several proteins involved in regulating neuronal activity, including the accessory subunits for voltage-gated ion channels and neuregulin, both of which play important roles in GABAergic neurons (Wong et al., 2005; Kim et al., 2007; Kim et al., 2011; Fleck et al., 2012; Sachse et al., 2013). NaV $\beta 2$ controls membrane localization of the sodium channel NaV1.1 to facilitate electrical excitability (Kovacs et al., 2010; Huth and Alzheimer, 2012), whereas neuregulin 1 stimulates GABA release (Wen et al., 2010). Reduction of either protein promotes epileptogenesis (Yu et al., 2006; Cheah et al., 2012; Tan et al., 2012). With multiple activityregulating proteins dependent on BACE processing, any process that impairs this function could alter the normal balance of excitability in the brain.

Our findings may also offer a new perspective on the association between seizures and AD in the clinical literature. Epidemiological studies have revealed that seizure risk is increased 87 -fold in patients with early-onset AD (Amatniek et al., 2006). Seizure risk in patients with late-onset $\mathrm{AD}$ drops to only threefold, offset in part because seizure risk for the entire population increases with age. The risk disparity suggests that there may be different mechanisms underlying the predisposition for seizure in each population. Inherited mutations may exert $A \beta$-independent effects during circuit formation that predispose the network to hypersynchrony. Absent this developmental influence, patients with late-onset disease may be more resistant to seizures until the network becomes severely damaged. In both cases, lowering $\mathrm{A} \beta$ may alleviate the pathological and cognitive progression of $\mathrm{AD}$, but our data suggest that this peptide may be the wrong target for alleviating hypersynchrony.

\section{References}

Amatniek JC, Hauser WA, DelCastillo-Castaneda C, Jacobs DM, Marder K, Bell K, Albert M, Brandt J, Stern Y (2006) Incidence and predictors of seizures in patients with Alzheimer's disease. Epilepsia 47:867-872. CrossRef Medline

Baglietto-Vargas D, Moreno-Gonzalez I, Sanchez-Varo R, Jimenez S, Trujillo-Estrada L, Sanchez-Mejias E, Torres M, Romero-Acebal M, Ruano D, Vizuete M, Vitorica J, Gutierrez A (2010) Calretinin interneurons are early targets of extracellular amyloid- $\beta$ pathology in PS1/A $\beta$ PP Alzheimer mice hippocampus. J Alzheimers Dis 21:119-132. CrossRef Medline

Bakker A, Krauss GL, Albert MS, Speck CL, Jones LR, Stark CE, Yassa MA, Bassett SS, Shelton AL, Gallagher M (2012) Reduction of hippocampal hyperactivity improves cognition in amnestic mild cognitive impairment. Neuron 74:467-474. CrossRef Medline

Bero AW, Yan P, Roh JH, Cirrito JR, Stewart FR, Raichle ME, Lee JM, Holtzman DM (2011) Neuronal activity regulates the regional vulnerability to amyloid- $\beta$ deposition. Nat Neurosci 14:750-756. CrossRef Medline

Busche MA, Eichhoff G, Adelsberger H, Abramowski D, Wiederhold KH, Haass C, Staufenbiel M, Konnerth A, Garaschuk O (2008) Clusters of hyperactive neurons near amyloid plaques in a mouse model of Alzheimer's disease. Science 321:1686-1689. CrossRef Medline

Busche MA, Chen X, Henning HA, Reichwald J, Staufenbiel M, Sakmann B, Konnerth A (2012) Critical role of soluble amyloid- $\beta$ for early hippocampal hyperactivity in a mouse model of Alzheimer's disease. Proc Natl Acad Sci U S A 109:8740-8745. CrossRef Medline

Cabrejo L, Guyant-Maréchal L, Laquerrière A, Vercelletto M, De la Fournière F, Thomas-Antérion C, Verny C, Letournel F, Pasquier F, Vital A, Checler F, Frebourg T, Campion D, Hannequin D (2006) Phenotype associated with APP duplication in five families. Brain 129:2966-2976. CrossRef Medline

Cheah CS, Yu FH, Westenbroek RE, Kalume FK, Oakley JC, Potter GB, Rubenstein JL, Catterall WA (2012) Specific deletion of NaV1.1 sodium channels in inhibitory interneurons causes seizures and premature death in a mouse model of Dravet syndrome. Proc Natl Acad Sci U S A 109: 14646-14651. CrossRef Medline

Cirrito JR, May PC, O’Dell MA, Taylor JW, Parsadanian M, Cramer JW, Audia JE, Nissen JS, Bales KR, Paul SM, DeMattos RB, Holtzman DM (2003) In vivo assessment of brain interstitial fluid with microdialysis reveals plaque-associated changes in amyloid- $\beta$ metabolism and half-life. J Neurosci 23:8844-8853. Medline

Cirrito JR, Yamada KA, Finn MB, Sloviter RS, Bales KR, May PC, Schoepp DD, Paul SM, Mennerick S, Holtzman DM (2005) Synaptic activity regulates interstitial fluid amyloid- $\beta$ levels in vivo. Neuron 48:913-922. CrossRef Medline

Cirrito JR, Disabato BM, Restivo JL, Verges DK, Goebel WD, Sathyan A, Hayreh D, D’Angelo G, Benzinger T, Yoon H, Kim J, Morris JC, Mintun MA, Sheline YI (2011) Serotonin signaling is associated with lower amyloid- $\beta$ levels and plaques in transgenic mice and humans. Proc Natl Acad Sci U S A 108:14968-14973. CrossRef Medline

Cobb SR, Buhl EH, Halasy K, Paulsen O, Somogyi P (1995) Synchronization of neuronal activity in hippocampus by individual GABAergic interneurons. Nature 378:75-78. CrossRef Medline

Corbett BF, Leiser SC, Ling HP, Nagy R, Breysse N, Zhang X, Hazra A, Brown JT, Randall AD, Wood A, Pangalos MN, Reinhart PH, Chin J (2013) Sodium channel cleavage is associated with aberrant neuronal activity and cognitive deficits in a mouse model of Alzheimer's disease. J Neurosci 33:7020-7026. CrossRef Medline

Cutsuridis V, Hasselmo M (2012) GABAergic contributions to gating, timing, and phase precession of hippocampal neuronal activity during theta oscillations. Hippocampus 22:1597-1621. CrossRef Medline

Del Vecchio RA, Gold LH, Novick SJ, Wong G, Hyde LA (2004) Increased seizure threshold and severity in young transgenic CRND8 mice. Neurosci Lett 367:164-167. CrossRef Medline

Ferraro TN, Golden GT, Smith GG, St Jean P, Schork NJ, Mulholland N, Ballas C, Schill J, Buono RJ, Berrettini WH (1999) Mapping loci for pentylenetetrazol-induced seizure susceptibility in mice. J Neurosci 19: 6733-6739. Medline

Fleck D, Garratt AN, Haass C, Willem M (2012) BACE1 dependent neuregulin processing: review. Curr Alzheimer Res 9:178-183. CrossRef Medline

Guo Q, Fu W, Sopher BL, Miller MW, Ware CB, Martin GM, Mattson MP 
(1999) Increased vulnerability of hippocampal neurons to excitotoxic necrosis in presenilin-1 mutant knock-in mice. Nat Med 5:101-106. CrossRef Medline

Guo Q, Zheng H, Justice NJ (2012) Central CRF system perturbation in an Alzheimer's disease knockin mouse model. Neurobiol Aging 33:26782691. CrossRef Medline

Guo Q, Li H, Cole AL, Hur JY, Li Y, Zheng H (2013) Modeling Alzheimer's disease in mouse without mutant protein overexpression: cooperative and independent effects of $\mathrm{A} \beta$ and tau. PLoS One 8:e80706. CrossRef Medline

Hangya B, Borhegyi Z, Szilágyi N, Freund TF, Varga V (2009) GABAergic neurons of the medial septum lead the hippocampal network during theta activity. J Neurosci 29:8094-8102. CrossRef Medline

Hiscock JJ, MacKenzie L, Willoughby JO (1996) Fos induction in subtypes of cerebrocortical neurons following single picrotoxin-induced seizures. Brain Res 738:301-312. CrossRef Medline

Hitt BD, Jaramillo TC, Chetkovich DM, Vassar R (2010) BACE1 ${ }^{-1-}$ mice exhibit seizure activity that does not correlate with sodium channel level or axonal localization. Mol Neurodegener 5:31. CrossRef Medline

Hoe HS, Lee HK, Pak DT (2012) The upside of APP at synapses. CNS Neurosci Ther 18:47-56. CrossRef Medline

Hong S, Quintero-Monzon O, Ostaszewski BL, Podlisny DR, Cavanaugh WT, Yang T, Holtzman DM, Cirrito JR, Selkoe DJ (2011) Dynamic analysis of amyloid $\beta$-protein in behaving mice reveals opposing changes in ISF versus parenchymal $\mathrm{A} \beta$ during age-related plaque formation. J Neurosci 31:15861-15869. CrossRef Medline

Hu X, Zhou X, He W, Yang J, Xiong W, Wong P, Wilson CG, Yan R (2010) BACE1 deficiency causes altered neuronal activity and neurodegeneration. J Neurosci 30:8819-8829. CrossRef Medline

Huth T, Alzheimer C (2012) Voltage-dependent Na + channels as targets of BACE1-implications for neuronal firing and beyond. Curr Alzheimer Res 9:184-188. CrossRef Medline

Jankowsky JL, Slunt HH, Gonzales V, Savonenko AV, Wen JC, Jenkins NA, Copeland NG, Younkin LH, Lester HA, Younkin SG, Borchelt DR (2005) Persistent amyloidosis following suppression of $A \beta$ production in a transgenic model of Alzheimer's disease. PLoS Med 2:e355. CrossRef Medline

Jankowsky JL, Younkin LH, Gonzales V, Fadale DJ, Slunt HH, Lester HA, Younkin SG, Borchelt DR (2007) Rodent A $\beta$ modulates the solubility and distribution of amyloid deposits in transgenic mice. J Biol Chem 282:22707-22720. CrossRef Medline

Jayadev S, Leverenz JB, Steinbart E, Stahl J, Klunk W, Yu CE, Bird TD (2010) Alzheimer's disease phenotypes and genotypes associated with mutations in presenilin 2. Brain 133:1143-1154. CrossRef Medline

Kamenetz F, Tomita T, Hsieh H, Seabrook G, Borchelt D, Iwatsubo T, Sisodia S, Malinow R (2003) APP processing and synaptic function. Neuron 37:925-937. CrossRef Medline

Kim DY, Carey BW, Wang H, Ingano LA, Binshtok AM, Wertz MH, Pettingell WH, He P, Lee VM, Woolf CJ, Kovacs DM (2007) BACE1 regulates voltage-gated sodium channels and neuronal activity. Nat Cell Biol 9:755-764. CrossRef Medline

Kim DY, Gersbacher MT, Inquimbert P, Kovacs DM (2011) Reduced sodium channel NaV1.1 levels in BACE1-null mice. J Biol Chem 286:81068116. CrossRef Medline

Klaassen A, Glykys J, Maguire J, Labarca C, Mody I, Boulter J (2006) Seizures and enhanced cortical GABAergic inhibition in two mouse models of human autosomal dominant nocturnal frontal lobe epilepsy. Proc Natl Acad Sci U S A 103:19152-19157. CrossRef Medline

Kobayashi D, Zeller M, Cole T, Buttini M, McConlogue L, Sinha S, Freedman S, Morris RG, Chen KS (2008) BACE1 gene deletion: impact on behavioral function in a model of Alzheimer's disease. Neurobiol Aging 29:861873. CrossRef Medline

Köhler C, Ebert U, Baumann K, Schroder H (2005) Alzheimer's disease-like neuropathology of gene-targeted APP-SLxPS1mut mice expressing the amyloid precursor protein at endogenous levels. Neurobiol Dis 20:528540. CrossRef Medline

Kovacs DM, Gersbacher MT, Kim DY (2010) Alzheimer's secretases regulate voltage-gated sodium channels. Neurosci Lett 486:68-72. CrossRef Medline

Lalonde R, Dumont M, Staufenbiel M, Strazielle C (2005) Neurobehavioral characterization of APP23 transgenic mice with the SHIRPA primary screen. Behav Brain Res 157:91-98. CrossRef Medline

Larner AJ, Doran M (2006) Clinical phenotypic heterogeneity of Alzhei- mer's disease associated with mutations of the presenilin-1 gene. J Neurol 253:139-158. CrossRef Medline

Levites Y, Das P, Price RW, Rochette MJ, Kostura LA, McGowan EM, Murphy MP, Golde TE (2006a) Anti-A $\beta 42$ - and anti-A $\beta 40$-specific mAbs attenuate amyloid deposition in an Alzheimer disease mouse model. J Clin Invest 116:193-201. CrossRef Medline

Levites Y, Smithson LA, Price RW, Dakin RS, Yuan B, Sierks MR, Kim J, McGowan E, Reed DK, Rosenberry TL, Das P, Golde TE (2006b) Insights into the mechanisms of action of anti- $\mathrm{A} \beta$ antibodies in Alzheimer's disease mouse models. FASEB J 20:2576-2578. CrossRef Medline

Loreth D, Ozmen L, Revel FG, Knoflach F, Wetzel P, Frotscher M, Metzger F, Kretz O (2012) Selective degeneration of septal and hippocampal GABAergic neurons in a mouse model of amyloidosis and tauopathy. Neurobiol Dis 47:1-12. CrossRef Medline

Mayford M, Bach ME, Huang YY, Wang L, Hawkins RD, Kandel ER (1996) Control of memory formation through regulated expression of a CaMKII transgene. Science 274:1678-1683. CrossRef Medline

Menéndez M (2005) Down syndrome, Alzheimer's disease and seizures. Brain Dev 27:246-252. CrossRef Medline

Minkeviciene R, Rheims S, Dobszay MB, Zilberter M, Hartikainen J, Fülöp L, Penke B, Zilberter Y, Harkany T, Pitkänen A, Tanila H (2009) Amyloid $\beta$-induced neuronal hyperexcitability triggers progressive epilepsy. J Neurosci 29:3453-3462. CrossRef Medline

Noebels J (2011) A perfect storm: converging paths of epilepsy and Alzheimer's dementia intersect in the hippocampal formation. Epilepsia 52:39 46. CrossRef Medline

Palop JJ, Mucke L (2009) Epilepsy and cognitive impairments in Alzheimer disease. Arch Neurol 66:435-440. CrossRef Medline

Palop JJ, Mucke L (2010) Amyloid- $\beta$-induced neuronal dysfunction in Alzheimer's disease: from synapses toward neural networks. Nat Neurosci 13:812-818. CrossRef Medline

Palop JJ, Chin J, Roberson ED, Wang J, Thwin MT, Bien-Ly N, Yoo J, Ho KO, Yu GQ, Kreitzer A, Finkbeiner S, Noebels JL, Mucke L (2007) Aberrant excitatory neuronal activity and compensatory remodeling of inhibitory hippocampal circuits in mouse models of Alzheimer's disease. Neuron 55:697-711. CrossRef Medline

Racine RJ (1972) Modification of seizure activity by electrical stimulation. II. Motor seizure. Electroencephalogr Clin Neurophysiol 32:281-294. CrossRef Medline

Ramos B, Baglietto-Vargas D, del Rio JC, Moreno-Gonzalez I, Santa-Maria C, Jimenez S, Caballero C, Lopez-Tellez JF, Khan ZU, Ruano D, Gutierrez A, Vitorica J (2006) Early neuropathology of somatostatin/NPY GABAergic cells in the hippocampus of a PS1xAPP transgenic model of Alzheimer's disease. Neurobiol Aging 27:1658-1672. CrossRef Medline

Roberson ED, Halabisky B, Yoo JW, Yao J, Chin J, Yan F, Wu T, Hamto P, Devidze N, Yu GQ, Palop JJ, Noebels JL, Mucke L (2011) Amyloid- $\beta$ / Fyn-induced synaptic, network, and cognitive impairments depend on tau levels in multiple mouse models of Alzheimer's disease. J Neurosci 31:700-711. CrossRef Medline

Rodgers SP, Born HA, Das P, Jankowsky JL (2012) Transgenic APP expression during postnatal development causes persistent locomotor hyperactivity in the adult. Mol Neurodegener 7:28. CrossRef Medline

Sachse CC, Kim YH, Agsten M, Huth T, Alzheimer C, Kovacs DM, Kim DY (2013) BACE1 and presenilin/ $\gamma$-secretase regulate proteolytic processing of KCNE1 and 2, auxiliary subunits of voltage-gated potassium channels. FASEB J 27:2458-2467. CrossRef Medline

Sanchez P, Zhu L, Verret L, Vossel K, Orr A, Cirrito J, Devidze N, Ho K, Yu G, Palop J, Mucke L (2012) Levetiracetam suppresses neuronal network dysfunction and reverses synaptic and cognitive deficits in an Alzheimer's disease model. Proc Natl Acad Sci U S A 109):E2895-E2903. CrossRef

Snider BJ, Norton J, Coats MA, Chakraverty S, Hou CE, Jervis R, Lendon CL, Goate AM, McKeel DW Jr, Morris JC (2005) Novel presenilin 1 mutation $(\mathrm{S} 170 \mathrm{~F})$ causing Alzheimer disease with Lewy bodies in the third decade of life. Arch Neurol 62:1821-1830. CrossRef Medline

Takahashi H, Brasnjevic I, Rutten BP, Van Der Kolk N, Perl DP, Bouras C, Steinbusch HW, Schmitz C, Hof PR, Dickstein DL (2010) Hippocampal interneuron loss in an APP/PS1 double mutant mouse and in Alzheimer's disease. Brain Struct Funct 214:145-160. CrossRef Medline

Tan GH, Liu YY, Hu XL, Yin DM, Mei L, Xiong ZQ (2012) Neuregulin 1 represses limbic epileptogenesis through ErbB4 in parvalbuminexpressing interneurons. Nat Neurosci 15:258-266. CrossRef Medline

Verret L, Mann EO, Hang GB, Barth AM, Cobos I, Ho K, Devidze N, Masliah 
E, Kreitzer AC, Mody I, Mucke L, Palop JJ (2012) Inhibitory interneuron deficit links altered network activity and cognitive dysfunction in Alzheimer model. Cell 149:708-721. CrossRef Medline

Wang A, Das P, Switzer RC 3rd, Golde TE, Jankowsky JL (2011) Robust amyloid clearance in a mouse model of Alzheimer's disease provides novel insights into the mechanism of amyloid- $\beta$ immunotherapy. J Neurosci 31:4124-4136. CrossRef Medline

Wang Z, Wang B, Yang L, Guo Q, Aithmitti N, Songyang Z, Zheng H (2009) Presynaptic and postsynaptic interaction of the amyloid precursor protein promotes peripheral and central synaptogenesis. J Neurosci 29: 10788-10801. CrossRef Medline

Wen L, Lu YS, Zhu XH, Li XM, Woo RS, Chen YJ, Yin DM, Lai C, Terry AV Jr, Vazdarjanova A, Xiong WC, Mei L (2010) Neuregulin 1 regulates pyramidal neuron activity via ErbB4 in parvalbumin-positive interneurons. Proc Natl Acad Sci U S A 107:1211-1216. CrossRef Medline

Westmark CJ (2013) What's hAPPening at synapses? The role of amyloid $\beta$-protein precursor and $\beta$-amyloid in neurological disorders. Mol Psychiatry 18:425-434. CrossRef Medline

Westmark CJ, Westmark PR, Beard AM, Hildebrandt SM, Malter JS (2008) Seizure susceptibility and mortality in mice that over-express amyloid precursor protein. Int J Clin Exp Pathol 1:157-168. Medline
Wong HK, Sakurai T, Oyama F, Kaneko K, Wada K, Miyazaki H, Kurosawa M, De Strooper B, Saftig P, Nukina N (2005) $\beta$ Subunits of voltagegated sodium channels are novel substrates of $\beta$-site amyloid precursor protein-cleaving enzyme (BACE1) and $\gamma$-secretase. J Biol Chem 280: 23009-23017. CrossRef Medline

Young-Pearse TL, Chen AC, Chang R, Marquez C, Selkoe DJ (2008) Secreted APP regulates the function of full-length APP in neurite outgrowth through interaction with integrin $\beta 1$. Neural Dev 3:15. CrossRef Medline

Yu FH, Mantegazza M, Westenbroek RE, Robbins CA, Kalume F, Burton KA, Spain WJ, McKnight GS, Scheuer T, Catterall WA (2006) Reduced sodium current in GABAergic interneurons in a mouse model of severe myoclonic epilepsy in infancy. Nat Neurosci 9:1142-1149. CrossRef Medline

Zheng H, Koo EH (2011) Biology and pathophysiology of the amyloid precursor protein. Mol Neurodegener 6:27. CrossRef Medline

Ziyatdinova S, Gurevicius K, Kutchiashvili N, Bolkvadze T, Nissinen J, Tanila H, Pitkänen A (2011) Spontaneous epileptiform discharges in a mouse model of Alzheimer's disease are suppressed by antiepileptic drugs that block sodium channels. Epilepsy Res 94:75-85. CrossRef Medline 